\title{
The Tiehchanshan structure of NW Taiwan: A potential geological reservoir for $\mathrm{CO}_{2}$ sequestration
}

\author{
Kenn-Ming Yang ${ }^{1, *}$, Bo-Iuan Chuang ${ }^{1}$, Ching-Yun Hsieh ${ }^{1}$, Bee-Der Yuan ${ }^{1}$, Hsin-Hsiu Ting ${ }^{1,2}$, and \\ Jar-Ben Wang ${ }^{2}$
}

${ }^{1}$ Department of Earth Sciences, National Cheng Kung University, Tainan, Taiwan

${ }^{2}$ Exploration and Development Research Institute, CPC Corporation, Taiwan, Miaoli, Taiwan

\section{Article history:}

Received 26 March 2012

Revised 18 May 2017

Accepted 25 May 2017

Keywords:

Carbon dioxide sequestration, Structural geology, Sequence stratigraphy,

Tiehchanshan structure

Citation:

Yang, K.-M., B.-I. Chuang, C.-Y. Hsieh, B.-D. Yuan, H.-H. Ting, and J.-B. Wang, 2017: The Tiehchanshan structure of NW Taiwan: A potential geological reservoir for $\mathrm{CO}_{2}$ sequestration. Terr. Atmos. Ocean. Sci., 28, 923-941, doi: 10.3319/ TAO.2017.05.25.01

\begin{abstract}
The Tiehchanshan structure is the largest gas-field in the outer foothills of northwestern Taiwan and has been regarded as the best site for $\mathrm{CO}_{2}$ sequestration. This study used a grid of seismic sections and wellbore data to establish a new 3-D geometry of subsurface structure, which was combined with lithofacies characters of the target reservoir rock, the Yutengping Sandstone, to build a geological model for $\mathrm{CO}_{2}$ sequestration. On the surface, the Tiehchanshan structure is characterized by two segmented anticlines offset by a tear fault. The subsurface geometry of the Tiehchanshan structure is, however, composed of two thrust-related anticlines with opposite vergence and laterally increasing fold symmetry toward each other. The folds are softly linked via the transfer zone in the subsurface, implying that the suspected tear fault in the surface transfer zone may not exist in the subsurface. The Yutengping Sandstone is composed of several sandstone units characterized by coarsening-upward cycles. The sandstone member can be further divided into four well-defined sandstone layers, separated by laterally continuous shale layers. In view of the structural and stratigraphic characteristics, the optimum area for $\mathrm{CO}_{2}$ injection and storage is in the structurally high in the northern part of the Tiehchanshan structure. The integrity of the closure and the overlying seal are not disrupted by the pre-orogenic high-angle faults. On the other hand, a thick continuous shale layer within the Yutengping Sandstone isolates the topmost sandy layer from the underlying ones and gives another important factor to the $\mathrm{CO}_{2}$ injection simulation.
\end{abstract}

\section{INTRODUCTION}

For carbon dioxide $\left(\mathrm{CO}_{2}\right)$ sequestration in the subsurface, fault-related folds are important sites for storage of $\mathrm{CO}_{2}$ either in saline aquifers or in existing oil and gas fields (Baines and Worden 2004). In the fold-and-thrust belt of northwestern Taiwan, compressional stress has resulted in several thrust-related HC-accumulating structures. Most of thrust-related folds are segmented and geometrically affected by a set of pre-existing transcurrent faults (Chinese Petroleum Corporation 1994; Yang et al. 1994, 1996, 1997). In the southernmost part of the structural domain, the largest gas-field in Taiwan, the Tiehchanshan structure, is one of the anticlines in the frontal part of the fault-and-thrust belt. As natural gas reserved in the production field is getting de-

\footnotetext{
* Corresponding author

E-mail:kmyang@mail.ncku.edu.tw
}

pleted, the owner, CPC Corp., Taiwan, has been using the structure for natural gas injection and storage. An internal assessment of the oil company suggests that reservoirs, either of gas-production or saline aquifers, in the anticlinal structures are the most appropriate for $\mathrm{CO}_{2}$ storage in northwestern Taiwan ( $\mathrm{Wu}$ et al. 2007). The assessment further pointed out that the optimum depth for $\mathrm{CO}_{2}$ storage is around 800 - 1500 m deep at which the Upper Pliocene and Lower Pleistocene have been penetrated. Therefore, the reservoir of saline aquifer in the shallow part of the structure should be the best option for $\mathrm{CO}_{2}$ storage in northwestern Taiwan.

Although the Tiehchanshan structure was often deemed a fold with simple and intact shape, various interpretations and reconstructions for the subsurface cross-sectional geometry have been proposed (Suppe and Namson 1979; Namson 1981; Hung and Wiltschko 1993; Yang et al. 1994, 2007; 
Chung 1996) and its 3-D geometry, kinematics and forming mechanism remain controversial (Tzeng et al. 2003; Wu 2010). One of the main purposes of this study is to use a grid of seismic sections and wellbore data to establish a 3-D geometry of the fold and the fold-forming thrusts. Another purpose is to analyze lithofacies variation of the target reservoirs of the Upper Pliocene Yutengping Sandstone and its cap rock, the Lower Pleistocene Chinshui Shale. There several reasons for the Yutengping Sandstone to be selected as the target reservoir. First, the depth of its structural closure is within the optimum interval for $\mathrm{CO}_{2}$ storage. Second, thickness and lithofacies of net sandstones are uniform over the closure. Third, the cap rock, the Chinshui Shale directly overlying the reservoir, is characterized by its thickness of around $150 \mathrm{~m}$ and high percentage $(>80 \%)$ of shales. The reconstructed subsurface structure and facies features of the target reservoirs are then combined to build a geological model for $\mathrm{CO}_{2}$ sequestration.

\section{REGIONAL GEOLOGY}

\subsection{Tectonic Settings of Foothills Belt}

The foothills belt in northwestern Taiwan is in the frontal part of the fold-and-thrust belt (Ho 1982) (Fig. 1). The deformation front of the belt now is in the offshore area (Huang 1987; Yuan et al. 1989; Huang et al. 1993). Fold tightness decreases from east to west in the belt. While the inner belt is characterized by tight or even overturned fold structure, open folds are predominant in the outer belt and the age of outcropped strata is not older than Late Miocene. The outer foothills belt is also characterized by two sets of intersecting fold and thrust structures, one striking NNESSW and the other NEE-SWW or E-W (Fig. 1).

Before the most recent orogeny, Taiwan had been located on the Eurasian passive margin. According to the studies of subsurface geology in both onshore and offshore areas, the western Taiwan encountered at least two phases of $\mathrm{Ce}$ nozoic extensional tectonics (Hsiao 1974; Tang 1977; Sun 1982; Leu et al. 1985; Chow et al. 1986, 1987, 1988; Yuan et al. 1989; Huang et al. 1993; Lin et al. 2003; Yang et al. 2006). The latest phase of extensional tectonics formed two rifted basins separated by a basement high (Tang 1977; Sun 1982; Yuan et al. 1989; Lin et al. 2003; Yang et al. 2006). The northern rifted basin, the Taihsi Basin, started to develop at the Middle Miocene time (Huang et al. 1993). The normal faulting in the basin continued until the encroaching orogenic belt moved westward into the present location (Yang et al. 2006). During the compressive tectonics, the E-W striking normal faults were reactivated and became high-angle thrusts (Namson 1981, 1984; Suppe 1984, 1986; Huang et al. 1993; Lee et al. 1993; Yang et al. 1994, 1996, 1997), which also formed one of the two sets of structures in the outer foothills belt (Huang et al. 1993; Lee et al. 1993; Yang et al. 1994, 1996, 1997). The folded Toukoshan Formation, the youngest formation of conglomerate in the fold-and-thrust belt, indicates that the threshold of latest phase of deformation in the foothills belt is not older than $1 \mathrm{~m} . \mathrm{y}$.

The study area covers the Tiehchanshan structure and its adjacent region in the outer foothills belt of northwestern Taiwan (Fig. 1). On the surface, the Tiehchanshan structure is characterized by two segmented anticlinal structures, the Tunghsiao anticline in the north and the Tiehchanshan anticline in the south. The anticlines might be offset in the transfer zone by a suspected tear fault with left lateral strike-slip motion (Fig. 2). On the surface, both anticlines are characterized by limbs dipping at angles mostly smaller than $10^{\circ}$, except in northwestern limb of the Tunghsiao anticline where strata are dipping at much higher angles of $30-50^{\circ}$. In general, the fold axes in the Tiehchanshan structure are mainly striking NNE-SSW. The northern segment of the Tunghsiao anticline turns into NE-SW and to the north merges with or terminates at the E-W striking Futoukeng fault, a high-angle thrust originated from inversion of a pre-existing normal fault (Namson 1981; Yang et al. 1994, 1996). The Futoukeng fault runs westward in a short distance, turns into NE-SW trend and extends southward into the offshore area. In the southern part of the Tiehchanshan structure, the fold axis of the Tiehchanshan anticline plunges to the south and deformation is transferred to the NNE-SSW striking Changhua fault. To the east of the Tiehchanshan structure, the Tunglo syncline separates the structure from the next hinterlandward Chuhuangkeng anticline, which is characterized by greater fold tightness and amplitude.

\subsection{Late Paleogene and Neogene Lithostratigraphic Units}

The subaerially exposed lithostratigraphic units of the Tiehchanshan structure are the Pleistocene and younger deposits. Older units are penetrated by drilled wells in the subsurface or outcropped in the other part of the fold-andthrust belt. Descriptions of the formations that appear in the structural cross-sections below are from the outcropped sections and subsurface wellbore data in the study area and its adjacent region. The lithostratigraphic units with their lithology in northwestern Taiwan are given in Table 1. Age of the formations ranges from the Late Oligocene to the Pleistocene. Abbreviations of the formations used in the crosssections are also given in the table. The target reservoir, the Yutengping Sandstone (Pytp), is one of the members of the Late Miocene to Pliocene Kueichulin Formation (Mkc). The member is characterized mainly by grey or greenish grey muddy sandstones and containing interlayers of sandstones and shales. Its detailed description of lithofacies is given in the chapter of reservoir stratigraphy below. The Chinshui Shale (Pcs) is characterized mainly by greenish grey to dark grey shales, with interlayers of sandstone and shales. In some parts of the unit, the shales are interbedded with 
fine-grained sandstones or siltstones. The unit has been regarded as the main cap rock and seal of the structure trap for $\mathrm{CO}_{2}$ storage and its thickness is in a range of $140-170 \mathrm{~m}$ in the study area.

\subsection{Previous Studies of Tiehchanshan Structure}

Elishewitz (1963) first regarded the Tiehchanshan structure as the result from buckling rather than faulting. Later, Chang (1974) delineated that the E-W striking Futoukeng fault gradually turns its way southward to N-S trend and cuts through the western limb of the structure. In the balanced cross-sections constructed by Suppe and Namson (1979) and Namson (1981), the Tiehchanshan structure is a typical fault-bend fold, with its lower flat along the base of the Wuchihshan Formation. In a balanced cross-section of Hung and Wiltschko (1993), a similar fault-bend fold with deeper lower flat was delineated. Later, the fault-bend fold model was questioned by Yang et al. (1994), who suggested that slip along the low-angle thrust necessary for creating the fold cannot explain the normal fault structures in the nearby offshore. They proposed detachment folding or thrust wedging as the alternatives to accommodate the contractional and neighboring extensional structures. Chung (1996) came to the same conclusion that no contractional structure found in the nearby offshore. His balanced cross-section also reveals that the Tunghsiao-Tiehchanshan fold is a fault-propagation fold generated by slip along the Futoukeng fault of listric shape, which cuts off the forelimb of fold upward to the surface. Lately, referring to interpreted seismic lines, a series of balanced cross-sections were constructed by Yang et al. (2007) to illustrate lateral variation in subsurface feature in the Tiehchanshan structure and its adjacent area. In their cross-sections, fold vergence is westward in the northern segment of the structure and eastward in the southern segment, with symmetrical geometry in the middle part of the structure.

Several contour maps of the gas-production reservoir, the Talu Sandstone, and the younger formations have been constructed for the purposes of exploration and production on the Tiehchanshan structure and some subsurface structural settings that do not appear on the surface were illustrated in theses maps. Structural maps of the Talu Sandstone top of Tzeng et al. (2003) show that the Tiehchanshan structure is an NE-SW striking fold, which is cut off by the Futoukeng fault on its northeastern side and segmented by a set of E-W or ESE-WNW striking transcurrent fault or normal fault. Their maps also show that the subsurface fold is twisted in its middle part and this makes the fold form two offset domains arranged in a left-lateral en echelon pattern. The location and sense of the offset might be related to that of the fold axes on the surface. In Wu's (2010) structural map of the Chinshui Shale top, the Tiehchanshan structure is composed of two independent fault-related folds arranged in a left-lateral en echelon pattern. In his interpretation, transcurrent faults or normal faults are not well developed at the level of the Chinshui Shale top.

\section{FOLD AND FAULT STRUCTURES}

\subsection{Seismic Interpretations and Structure Descriptions}

Figure 2 shows the location of seismic lines and drilled wells that were used for structural and stratigraphic interpretations in this study. All the seismic sections were converted from time to depth sections based on sonic logs that give travel time of seismic wave in the depth. The depth sections were loop-tied to make time-depth conversion consistent for all seismic sections. The sections then were adjusted to $1: 1$ ratio for vertical vs. horizontal scales. Details of the work of time-to-depth conversion were described in Chuang (2011). Such sections allow us to work, with theoretical models of angular relationship between fold and fault geometry (Suppe 1983; Suppe et al. 2004), on structural analysis of described fold and interpreted fault shapes. Below, the interpreted formation tops were determined by the drilled well data. We treat each formation boundary as an isochronous line in a structure of local scale in this study. According to

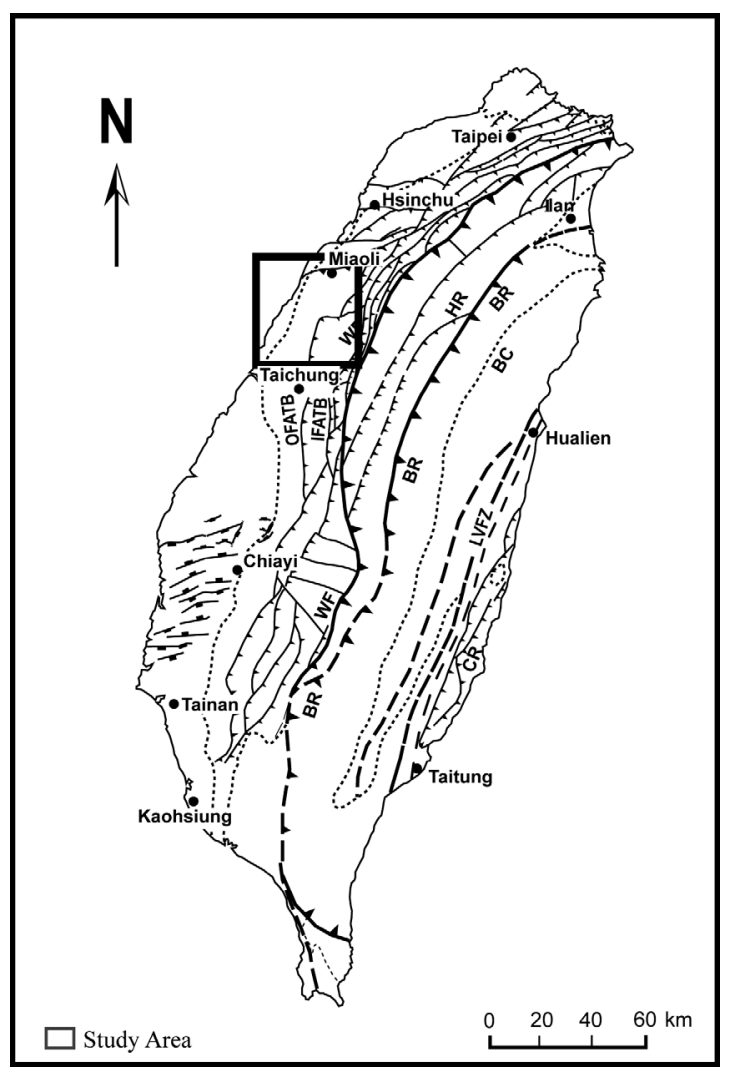

Fig. 1. Tectonic map of Taiwan. The study area of this paper is in the fold-and-thrust belt in northwestern Taiwan. WF, Western Foothills; HR, Hsuehshan Rang; BR, Backbone Range; BC, Basement Complex; LVFZ, Longitudinal Valley Fault Zone; CR, Coastal Range (modified from Yang et al. 2006). 


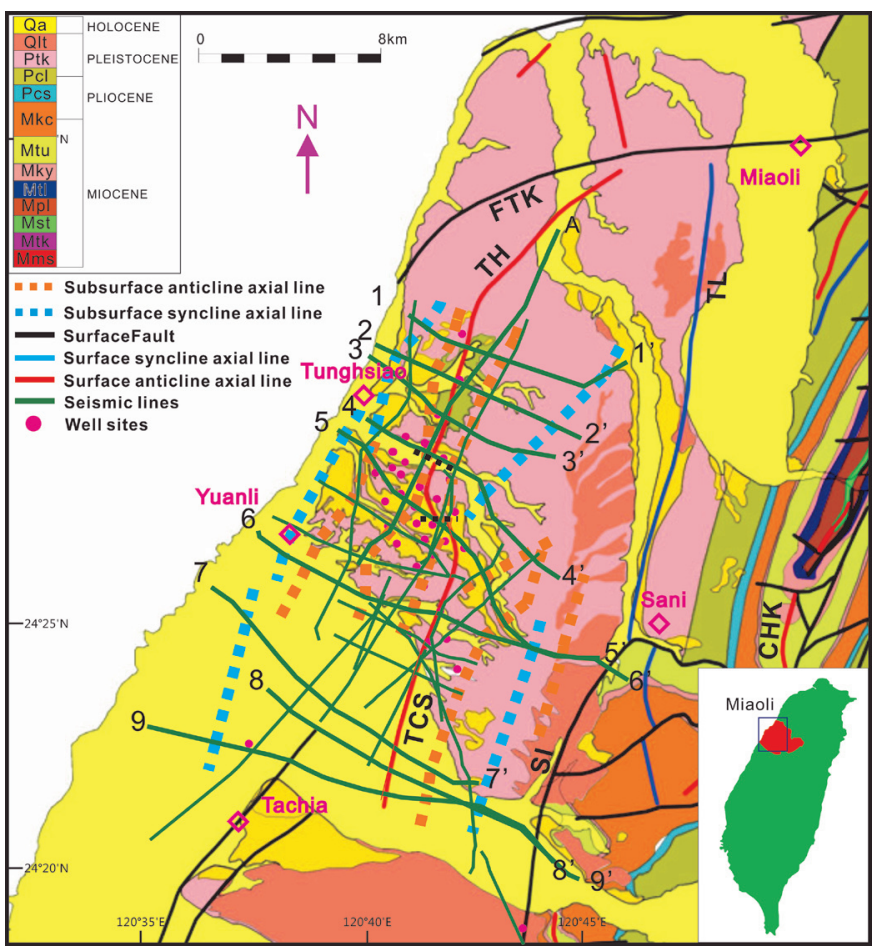

Fig. 2. Map of geological settings in the study area (from Chinese Petroleum Corporation 1994). Included are location of seismic lines and wells that were used in this paper. The compiled chronostratigraphic chart in northwestern Taiwan is shown in the upper left part of the map. On the surface, the Tiehchanshan structure is composed of two anticlines that are offset left-laterally by an E-W trend suspected tear fault. Also shown are the trend and a number of subsurface axial surfaces of the separated anticlines and in the transfer zone in between. The surface location of the axial surface is defined by projecting the subsurface axial surfaces in all sections up to the surface. Detailed descriptions and their structural implications are given in the chapter "Discussions". FTK: Futoukeng fault; TH, Tunghsiao anticline; TCS: Tiehchanshan anticline; TL: Tunglo syncline; SI; San-I thrust; CHK: Chuhuangkeng anticline.

Table 1. Lithostratigraphic units and the lithology of the Late Oligocene to Pleistocene formations.

\begin{tabular}{|c|c|c|c|c|}
\hline \multicolumn{2}{|c|}{ Chronostratigraphy } & \multicolumn{2}{|c|}{ Lithostratigraphic Units } & Lithology \\
\hline \multirow{2}{*}{\multicolumn{2}{|c|}{ Pleistocene }} & \multicolumn{2}{|c|}{ Toukoshan Formation (Ptk) } & $\begin{array}{l}\text { grayish to brownish white subgraywacke, grey to dark grey shales and conglomer- } \\
\text { ates }\end{array}$ \\
\hline & & \multicolumn{2}{|r|}{ Cholan Formation (Pch) } & $\begin{array}{l}\text { interlayers of sandstones (greenish to brownish grey and fine- to medium-grained } \\
\text { greywacke), siltstones and shales }\end{array}$ \\
\hline \multirow{3}{*}{ Pliocene } & & \multicolumn{2}{|r|}{ Chinshui Shale (Pcs) } & greenish grey to dark grey shales, with interlayers of sandstone and shales \\
\hline & \multirow[b]{2}{*}{ Lower } & \multirow{3}{*}{$\begin{array}{c}\text { Kueichulin } \\
\text { Formation } \\
\text { (Mkc) }\end{array}$} & Yutengping Sandstone (Pytp) & grey or greenish grey muddy sandstones and interlayers of sandstones and shales \\
\hline & & & Shiliufen Shale (Pslf) & dark grey or greenish grey shales and sandy shales \\
\hline \multirow{10}{*}{ Miocene } & \multirow[b]{2}{*}{ Upper } & & Kuantaoshan Sandstone (Mkts) & pale to dark grey muddy sandstones and interlayers of sandstones and shales. \\
\hline & & \multicolumn{2}{|c|}{ Shangfuchi Sandstone (Msf) } & $\begin{array}{l}\text { white medium- to coarse-grained massive loose sandstones with shales and inter- } \\
\text { layers of shale and sandstone }\end{array}$ \\
\hline & \multirow{3}{*}{ Middle } & \multicolumn{2}{|c|}{ Tungkeng Formation (Mtu) } & interlayered sandstones and shales \\
\hline & & \multicolumn{2}{|c|}{ Kuanyinshan Sandstone (Mky) } & $\begin{array}{l}\text { thick grey to pale grey and fine- to medium-grained sandstones with few thin } \\
\text { interbedded shales }\end{array}$ \\
\hline & & \multicolumn{2}{|r|}{ Talu Shale (Mtl) } & $\begin{array}{l}\text { grey to dark grey shales with few interbedded calcareous fine-grained sandstones } \\
\text { or siltstones of lenticular shape }\end{array}$ \\
\hline & \multirow{5}{*}{ Lower } & \multicolumn{2}{|r|}{ Peiliao Formation (Mpl) } & $\begin{array}{l}\text { thick very fine- to fine-grained greywacke or sub-greywacke sandstones interlay- } \\
\text { ered with dark green glauconite-bearing sandstones and thin grey shales }\end{array}$ \\
\hline & & \multicolumn{2}{|r|}{ Shihti Formation (Mst) } & $\begin{array}{l}\text { fine- to medium-grained sub-quartzites of grayish white color, with interbedded } \\
\text { grey shales }\end{array}$ \\
\hline & & \multicolumn{2}{|r|}{ Piling Shale (Mtk) } & thick and highly compacted shales of dark to heavy grey color \\
\hline & & \multicolumn{2}{|c|}{ Mushan Formation (Mms) } & $\begin{array}{l}\text { greyish white coarse- to medium-grained quartzites or sub-quartzites with thin } \\
\text { grey shale beds and interlayers of sandstone and shale }\end{array}$ \\
\hline & & \multicolumn{2}{|c|}{ Wuchihshan Formation (Ows) } & $\begin{array}{l}\text { white grey medium- to very coarse-grained sandstones with loose and sub-angular } \\
\text { sand grains }\end{array}$ \\
\hline
\end{tabular}


the theoretical presumptions of seismic interpretation (Vail et al. 1977; Hubbard et al. 1985), which have long been well tested and applied to many cases in the industry, isochronous lines can be traced along the reflectors as far as possible. As for the interpretation of fault in the subsurface, some fault planes were constrained by the drilled wells and the others were identified by the character of consistent termination of the reflectors. The rationale of interpretation of low-angle thrust in a seismic section can be referred to Shaw et al. (2005). The interpreted formation tops and fault planes in this study were also justified by loop-tie through all sections and drilled well data. The deepest formation top that can be constrained by drilled well is the top of Wuchihshan Formation. Interpreted sections that strike perpendicular to the fold axis were illustrated below. All seismic lines were grouped into three sets from north to south to demonstrate characteristic fold and fault features in different parts of the Tiehchanshan structure, i.e., the Tunghsiao anticline, structural transfer zone, and Tiehchanshan anticline.

Lines 1 - 3 (Fig. 3) This set of seismic sections run across the Tunghsiao anticline (Fig. 2) and show that the thickness of folded strata below the Chinshui Shale (Pcs) top is nearly equal and that the anticline is characterized by shorter and steeper western limb relative to eastern limb,

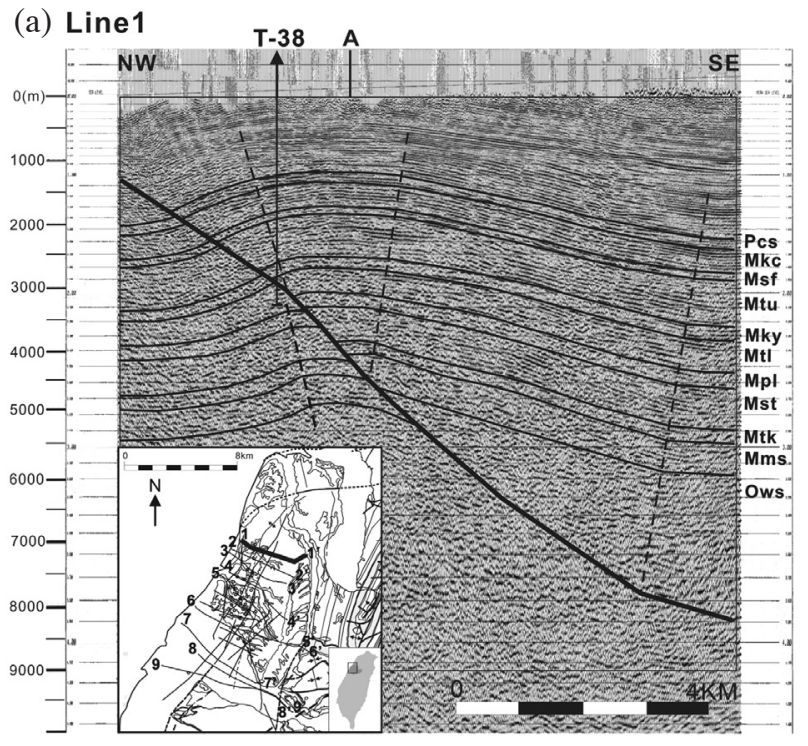

(b) Line2

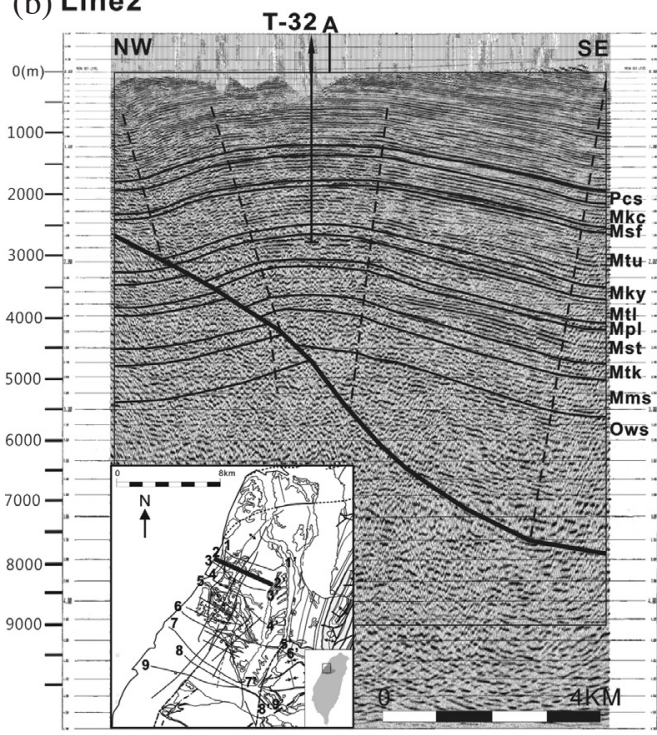

(c) Line3

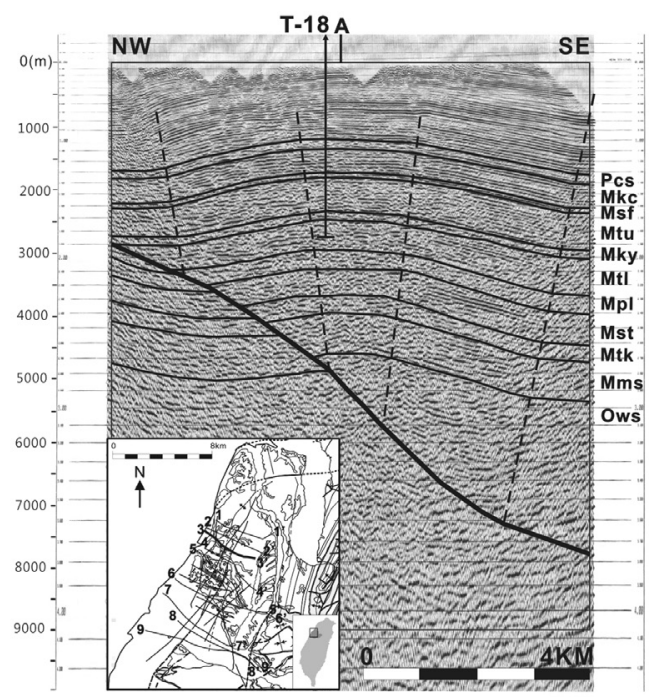

Fig. 3. Interpreted seismic sections of Lines $1-3$. The Tunghsiao anticline is characterized by short steeper forelimb and longer backlimb with gentle dip angle (a). The fold-forming fault is upthrusting toward the northwest, with multiple bends and decreasing-upward slip along the thrust. The geometry of thrust is not a simple step. The difference between the length of forelimb and backlimb of anticline is reduced and the dip angles of the fold-forming thrust with multiple bend are gentle toward the south (b) (c). Abbreviations of interpreted formations, as used in this section and the other sections below, can be referred to the chronostratigraphic chart in Fig. 2 and their lithology are described in Table 1. 
indicating westward vergence of folding. The anticline is cut through its western limb by an east-dipping high-angle thrust of multiple bends. The interpreted fault can be constrained by well T-38 in its shallow part and by the termination of reflectors for the lower part at which formation dip angles abruptly change on both sides of the fault. The fault bend is not a simple step; the upper flat of the fault cuts at shallow angle down to the Talu Formation and turns into a steeper ramp dipping. The fault cuts down to the depth below the Wuchihshan Formation (Ows) and rolls back to the lower flat. The slip along the fault plane decreases upward along the fault plane. Each fault bend corresponds to an axial surface in the hanging wall. There are some changes in structural features from north to south among the sections (Fig. 3): (1) the length of back limb is shorter and, though still indicating westward vergence, fold shape becomes more symmetrical; (2) for the major east-dipping thrust, the upper flat is deeper, and the lower flat is shallower, with shorter ramp of the fault; (3) the intersection between the upper flat and ramp of fault becomes deeper. In Line 3
(Fig. 3c), noticeable kink bend feature appears through the folded strata and axial surfaces between sharply bended straight panels can be well defined.

Lines 4 - 6 (Fig. 4), the lines would demonstrate the structural features in the area covering the southernmost part of the Tunghsiao anticline, the structural transfer zone and the northernmost part of the Tiehchanshan anticline. The sections (Fig. 4) show very different structural features from that in the lines to the north. First, the fault bend of the east-dipping thrust is nearly a simple step, with deeper upper flat and shallower lower flat, dipping at very low angle, and shorter ramp of fault. The simple step character is also indicated by that regional of the unfolded strata on both sides of the anticline is at the same structural level. Second, the forelimb and backlimb are about equal in length, but with shorter forelimb, and are longer than the crest. The sections (Fig. 4) also show that the crest of the folded strata is composed of several straight panels bounded by well-defined axial surfaces. The number of the axial surface is greater toawrd the south. Though the fold geometry
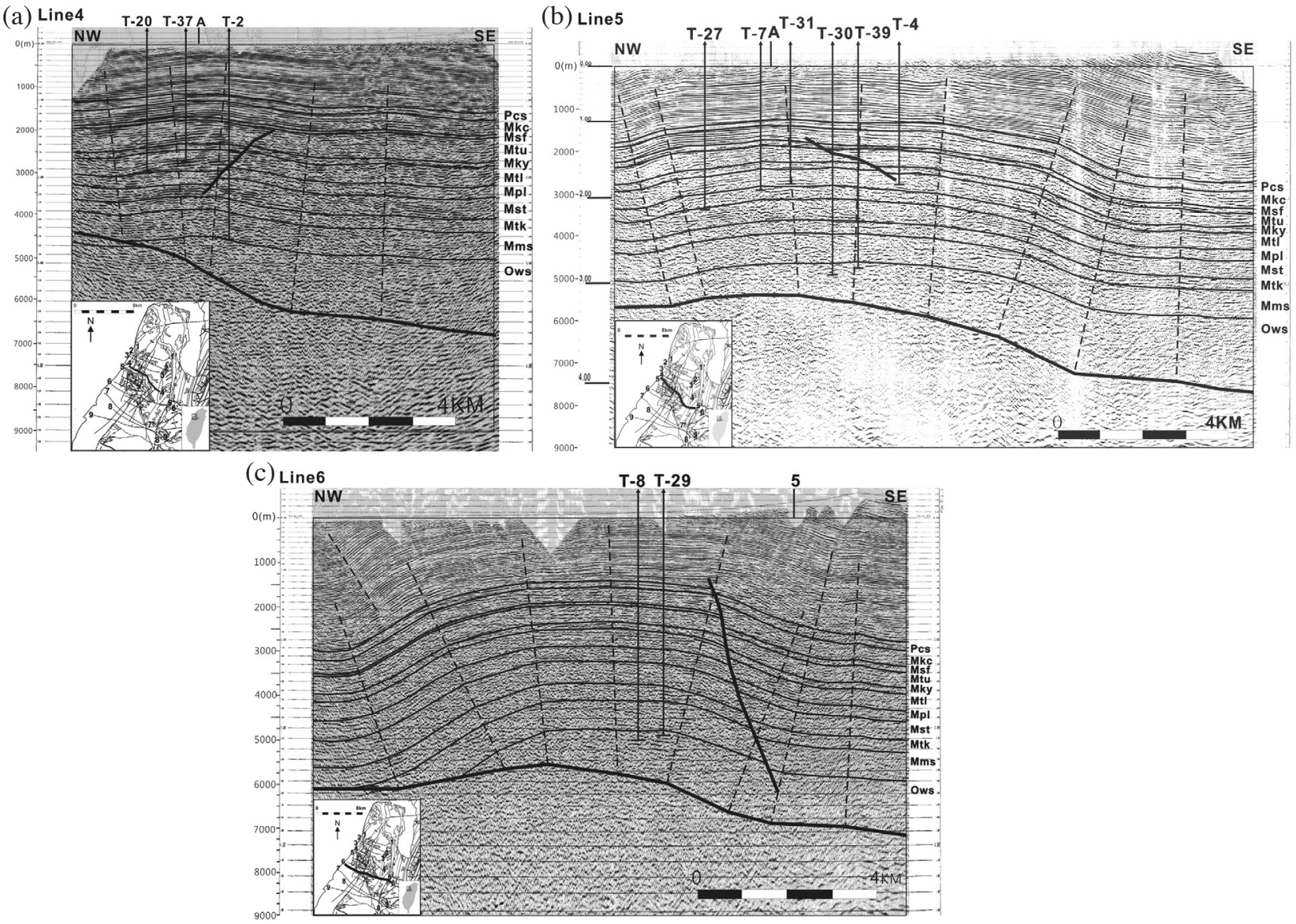

Fig. 4. Interpreted seismic sections of Lines 4 - 6. These sections run across the area between the southernmost part of the Tunghsiao anticline and the northernmost part of the Tiehchanshan anticline. The dip angle of the fold-forming fault is largely reduced and the fault shape is nearly a simple step (a). Accompanied by the simple-step thrust is a symmetric fold of the anticline and its shape still indicates westward vergence (b) (c). The anticline is characterized by multiple bends of fold shape. The symmetry and number of bend increase toward the south. The thrust ramp in Lines 5 (b) and 6 (c) has been upfolded, suggesting that the anticline may be also affected by deformation of fold to the south of the line. 
is nearly symmetrical, westward vergence can be identified by the longer backlimb, which is represented by the panel with the greatest dip angle at the easternmost part of the anticline, than the forelimb, which is represented by the panel with the greatest dip angle at the westernmost part of the anticline. The multiple bends of the anticline are related to slip along a low-angle thrust. While the lower flat of fault is dipping eastward at very low angle, the upper flat is dipping westward at very low angle and become bedding slip planes away from the anticlinal structure. The fault shape in Lines 5 and 6 (Figs. 4b, c) indicates that the upfolded thrust might be caused by slip along another lower thrust of simple step in the footwall. The multiple bends of the anticline also imply stacking thrusts underneath the structure.

Lines 7 - 9 (Fig. 5), the lines are located in the southern part of the Tiehchanshan anticline (Fig. 2) and show an asymmetric anticlinal structure (Fig. 5), of which the shorter and steeper eastern limb can be defined as the forelimb. The western limb is dipping at $10^{\circ}$ and is much longer than the eastern limb of the anticline. There is another steeper and short panel at the trailing part of western limb in Line 7
(Fig. 5a). Though the multiply bended western limb, the whole anticline is characterized by an asymmetric broad and obtuse chevron fold with eastward vergence. The eastern limb is cut off by a high-angle thrust, which is dipping to the west at $42-50^{\circ}$. Lines 8 and 9 are located to the south of Line 7 (Fig. 2) and show that the straight western limb (Figs. 5b, c). The strata younger than the Chinshui Shale (Pcs) are cut by an east-dipping low-angle thrust, resulting in gently increased thickness of strata in the shallowest part of the chevron fold. The strata in the footwall are folded and uptilted to the east, forming a local syncline, which in turn corresponds to the Tunglo syncline to the east of the Tiehchanshan structure.

\subsection{Fault-Related Fold Models}

Suppe (1983), Suppe and Medwedeff (1990), and Suppe et al. (2004) give theoretical equations of angular relationship between fold shape and fault bend in their quantitative models of various fault-related folds and display them with graphs for applications. In this study, almost all folds
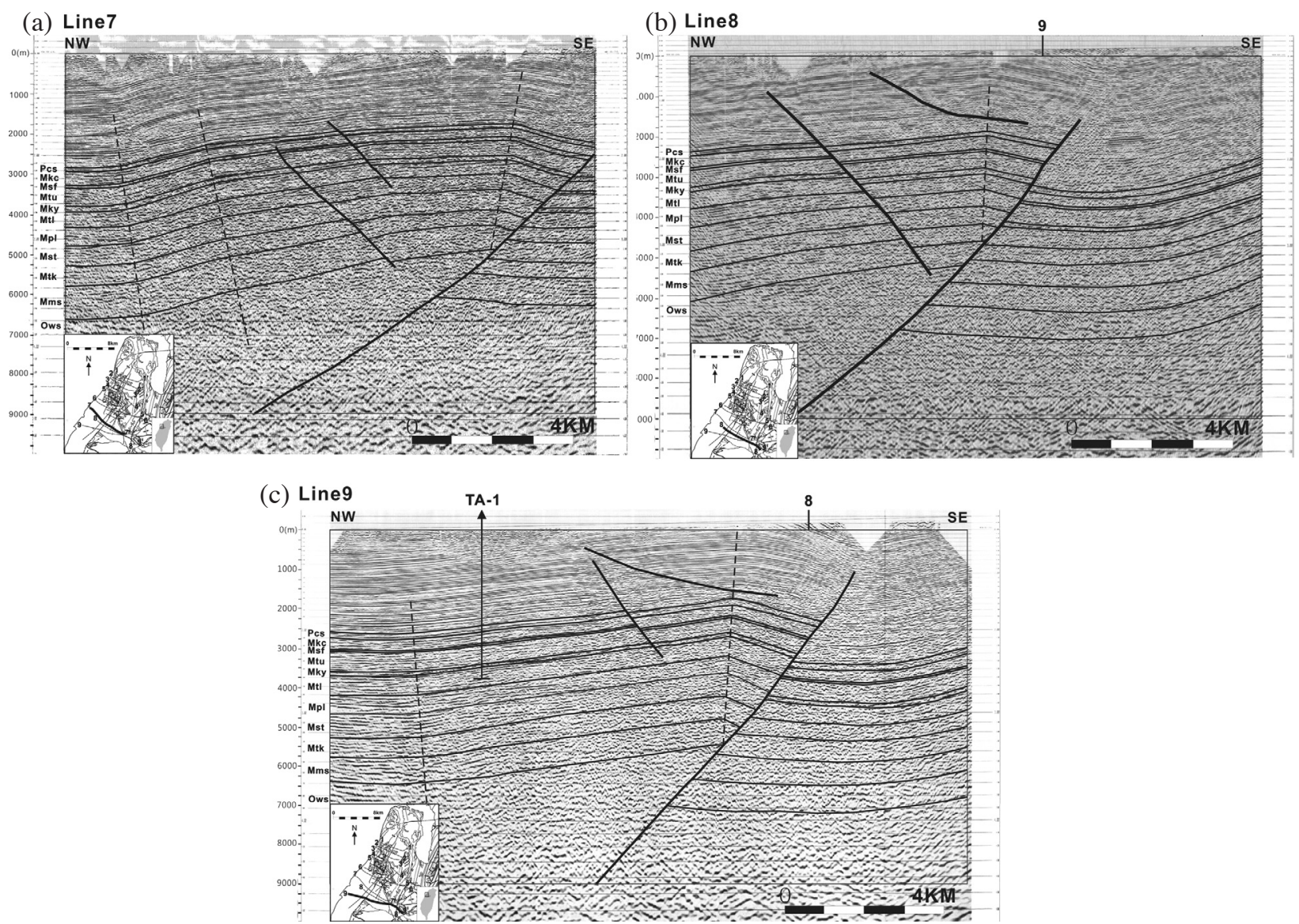

Fig. 5. Interpreted seismic sections of Lines 7 - 9. In these sections, the Tiehchanshan anticline appears as a chevron fold with short forelimb and much longer backlimb, indicating eastward vergence. There is another fold bend in the trailing part of backlimb in Line 7 (a). The fold-forming fault is a high-angle thrust with straight fault plane. A thrust with gentle dip angle occurs in the shallow part of the anticline crest in Lines 8 (b) and 9 (c). Slip of the thrust forms a local anticlinal structure and results in thickening strata in its hanging wall. 
in the sections are composed of straight panels, indicating kink type of fold geometry. All axial surfaces bisect the angle between the straight panels; therefore, the structures are formed by parallel folding, i.e., the layer thickness is conserved after deformation. Below, we only addressed the fold structures that are cut off by high-angle thrusts.

Observed fold and interpreted fault geometry in several sections across the Tunghsiao anticline are first analyzed and tested by the quantitative model of Suppe (1983) for fault-bend folding. We measured the internal bisecting angles of forelimb anticline $\left(\gamma_{f}\right)$ and backlimb syncline $\left(\gamma_{b}\right)$, angles of fault bend between upper flat and ramp $\left(\psi_{\mathrm{f}}\right)$ and between ramp and lower flat $\left(\psi_{b}\right)$, cutoff angles of forelimb $\left(\beta_{\mathrm{f}}\right)$ and backlimb $\left(\beta_{\mathrm{b}}\right)$, and cutoff angles of regional strata in the hanging wall of ramp $\left(\theta_{\mathrm{f}}\right)$ and lower flat $\left(\theta_{\mathrm{b}}\right)$ respectively. The measured angles were plotted in the graph of quantitative model (Suppe 1983) to test the validity of fault interpretation (Fig. 6). Table 2 shows the measured angles for Lines 1 - 4 with the difference between theoretical and measured values.

Anticlinal structure in the sections across the Tiehchanshan anticline (Fig. 5) is an asymmetric chevron fold with short forelimb and long backlimb. Higher structural level of regional strata in the hanging wall than that in the footwall, backlimb not parallel with thrust ramp and upsection decreasing slip along the thrust all indicate that the structure can be characterized as a non-simple-step fault-propagation fold of Suppe and Medwedeff (1990) with thrust breaking through the forelimb, rather than a typical fault-bend fold of Suppe (1983) or shear fault-bend fold of Suppe et al. (2004). We measured the internal bisecting angles of chevron fold $\left(\gamma^{*}\right)$ and backlimb syncline $\left(\gamma_{1}\right)$, cutoff angles of forelimb $\left(\beta_{2}\right)$ and backlimb $\left(\beta_{1}\right)$, and cutoff angles of regional strata in the footwall of ramp $\left(\theta_{2}\right)$. Measured angles are shown in Table 3. Plots of the measured angles in the graph of quantitative model of Suppe and Medwedeff (1990) (Fig. 7) indicate that the predicted fault-bend angle between lower flat and ramp $(\psi)$ and cutoff angle of the hanging wall by lower flat $\left(\theta_{1}\right)$ are much lower and greater than the theoretical ones respectively.

The quantitative model of Suppe and Medwedeff (1990) (Fig. 7) presumes no layer-parallel simple shear within the hanging wall strata $\left(S_{p}=\operatorname{tana}_{p}=0\right)$. We may use the equation relating $S_{p}$ with $\gamma^{*}, \gamma_{1}, \beta_{1}$, and $\theta_{2}$ [Eq. (5) in Suppe and Medwedeff (1990)] to calculate and obtain $S_{p}=-0.145$ and $\alpha_{p}=$ $8.3^{\circ}$ in Line $7, S_{p}=-0.059$ and $\alpha_{p}=3.4^{\circ}$ in Line 8 , and $S_{p}=$ -0.129 and $\alpha_{p}=7.4^{\circ}$ in Line 9 . The negative $S_{p}$ indicates that more extra bed length should be balanced for the shallower strata. We expect that, under such condition, more layerparallel shortening would happen after deformation and this can be achieved by local thrusting or thickening in the shallower strata. In Lines 8 and 9 (Figs. 5b, c), the east-dipping low-angle thrusting and the accompanied gently thickened strata in the shallowest part of the chevron fold might be produced by such extra shortening. In Line 7 (Fig. 5a), the low-angle thrust is not present; nonetheless, gently thickened strata in the shallowest part of the chevron fold still can be observed. Below, a trishear model for the formation of a fault-propagation fold would give further validation for our interpretation of the Tiehchanshan anticline.

\subsection{3-D Geometry}

Subsurface contour maps of the Kueichulin Formation top and the fault plane of the thrusting forming the Tunghsiao anticline were built based on the above interpreted and analyzed seismic sections. The geometry of southern boundary of the fault plane was constrained by the upper low-angle thrust in Line 6 (Fig. 4c). As for the fault plane of the thrusting forming the Tiehchanshan anticline, its 3-D geometry cannot be well constrained by three sections located in a narrow zone and thus were not illustrated in this paper.

The contour map of the Kueichulin Formation top (Fig. 8) shows a twisted anticlinal structure, including the entire Tunghsiao anticline to the north of the surface transfer zone and northern part of the Tiehchanshan anticline. The fold axis of the latter plunges to the south and is cut off by an E-W trending normal fault at its northern part. The fold axis is also offset in a sense of left-lateral from that of the Tunghsiao anticline to the north. The normal fault cutting off the fold axis actually is located to the south of the surface transfer zone. In the subsurface transfer zone, the strike of fold axis in the southern end of the Tunghsiao anticline turns into E-W and back to N-S in the northern part of the Tiehchanshan anticline to the south.

No normal fault cuts upward through the top of Kueichulin Formation in the middle part of the Tunghsiao anticline and only in its northwestern part the anticline is cut off by the NE-SW trending high-angle thrust. As indicated by variation in shape of thrust cutting off the forelimb of Tunghsiao anticline, the steep upper flat of the thrust becomes low-angle and deepens toward the south. It is noticeable that the strike of ramp and lower flat changes from NESW to NW-SE toward the surface transfer zone and turns back to NE-SW across the zone (Fig. 9).

\subsection{Kinematics: Trishear Models}

Trishear model has been proposed to address the problem of fold structure that is not characterized by kink fold (Erslev 1991). Normally such fold structure appears in the tectonic regions with basement-involved structural style. Lately, quantitative models for geometry and kinematics of trishear fault-related fold have been proposed (Hardy and Ford 1997; Allmendinger 1998; Zehnder and Allmendinger 2000; Cristallini and Allmendinger 2001) for application of folding in general.

Fold of Tiehchanshan structure in the areas that are 


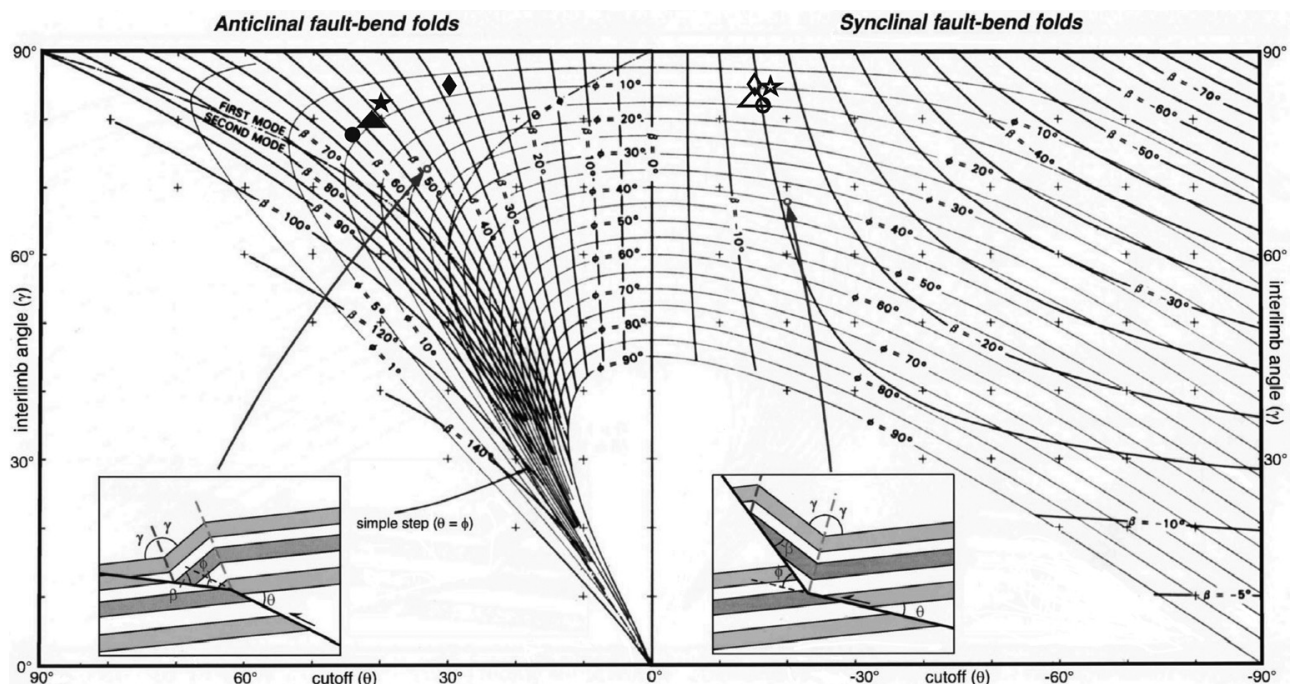

Fig. 6. Calculated fault-bend angles in the shallow $\left(\psi_{\mathrm{f}}\right)$ (solid symbols) and deep $\left(\psi_{\mathrm{b}}\right)$ (hollow symbols) parts of the fold-forming fault in the section of Lines 1, 2, 3, and 4 by plotting measured internal bisecting angles of forelimb anticline $\left(\gamma_{\mathrm{f}}\right)$ - hanging wall cutoff angle by ramp $\left(\theta_{\mathrm{f}}\right)$ and backlimb syncline $\left(\gamma_{\mathrm{b}}\right)$ - hanging wall cutoff angle by lower flat $\left(\theta_{\mathrm{b}}\right)$ respectively in the graph of Suppe (1983) and Shaw et al. (2005). Please see detailed discussions in the text. The symbols representing the fault bend structure in the sections are: $\mathbf{O}$, Line $1 ; \boldsymbol{\Delta}$, Line $2 ; \star$, Line 3 ; $\bullet$, Line 4 .

Table 2. Measured angles of fold and fault shapes in the lines across the Tunghsiao anticline. Numbers in the parentheses represent the difference between the theoretical and measured angles.

\begin{tabular}{l|cccccccc}
\hline & $\gamma_{\mathrm{f}}$ & $\boldsymbol{\gamma}_{\mathrm{b}}$ & $\boldsymbol{\psi}_{\mathrm{f}}$ & $\boldsymbol{\psi}_{\mathrm{b}}$ & $\boldsymbol{\theta}_{\mathrm{f}}$ & $\boldsymbol{\theta}_{\mathrm{b}}$ & $\boldsymbol{\beta}_{\mathrm{f}}$ & $\boldsymbol{\beta}_{\mathbf{b}}$ \\
\hline Line 1 & $78^{\circ}$ & $82^{\circ}$ & $12^{\circ}\left(2^{\circ}\right)$ & $18^{\circ}\left(1^{\circ}\right)$ & $45^{\circ}$ & $17^{\circ}$ & $57^{\circ}$ & $17^{\circ}\left(1^{\circ}\right)$ \\
Line 2 & $80^{\circ}$ & $83^{\circ}$ & $10^{\circ}$ & $15^{\circ}\left(2^{\circ}\right)$ & $41^{\circ}$ & $15^{\circ}$ & $56^{\circ}\left(2^{\circ}\right)$ & $14^{\circ}$ \\
Line 3 & $83^{\circ}$ & $85^{\circ}$ & $8^{\circ}$ & $12^{\circ}\left(2^{\circ}\right)$ & $40^{\circ}$ & $18^{\circ}$ & $49^{\circ}\left(1^{\circ}\right)$ & $18^{\circ}\left(1^{\circ}\right)$ \\
Line 4 & $85^{\circ}$ & $85^{\circ}$ & $8^{\circ}$ & $12^{\circ}\left(1^{\circ}\right)$ & $30^{\circ}$ & $15^{\circ}$ & $30^{\circ}\left(3^{\circ}\right)$ & $15^{\circ}$ \\
\hline
\end{tabular}

Table 3. Measured angles of fold and fault shapes in the lines across the Tiehchanshan anticline.

\begin{tabular}{c|cccc}
\hline & $\boldsymbol{\gamma}^{*}$ & $\boldsymbol{\gamma}_{1}$ & $\boldsymbol{\beta}_{1}$ & $\boldsymbol{\theta}_{2}$ \\
\hline Line 7 & $80^{\circ}$ & $84^{\circ}$ & $35^{\circ}$ & $44^{\circ}$ \\
Line 8 & $81^{\circ}$ & $85^{\circ}$ & $37^{\circ}$ & $49^{\circ}$ \\
Line 9 & $77^{\circ}$ & $82^{\circ}$ & $40^{\circ}$ & $49^{\circ}$ \\
\hline
\end{tabular}
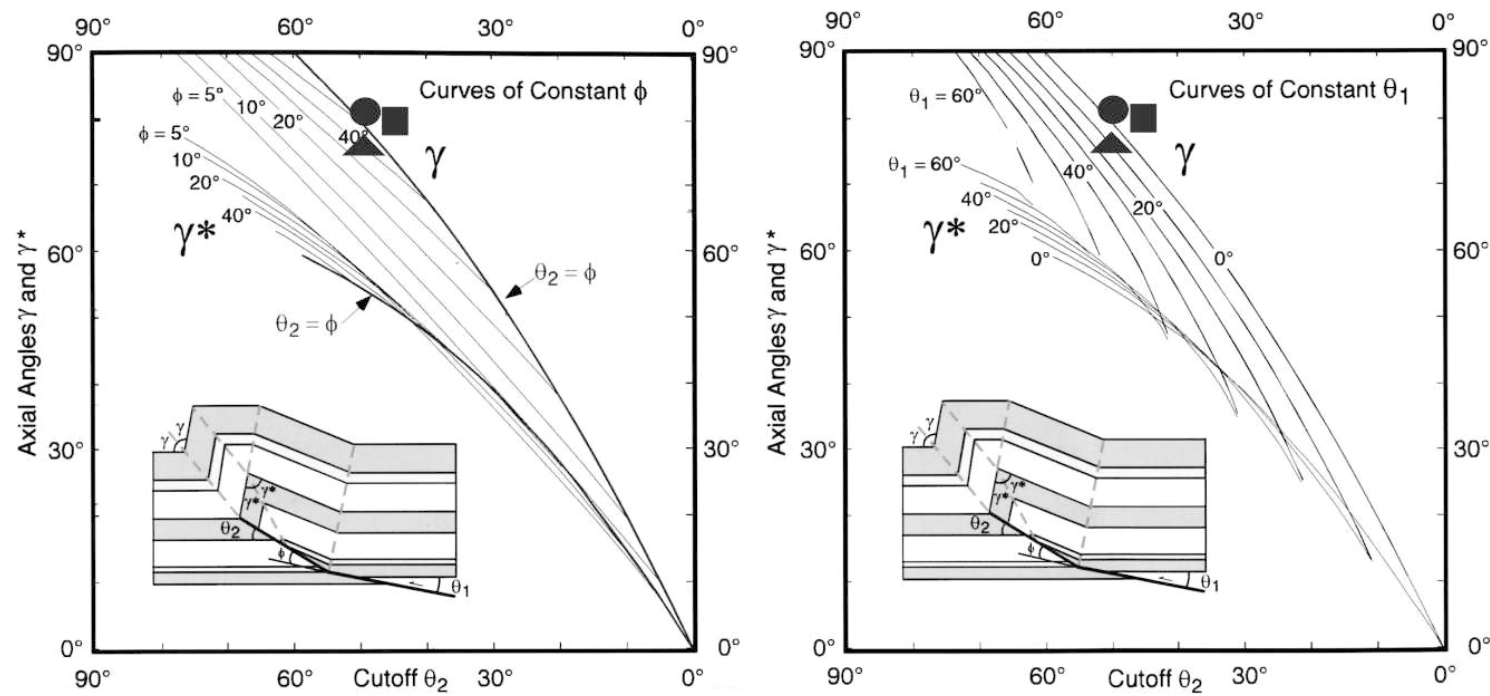

Fig. 7. Predicted fault-bend angle between lower flat and $\operatorname{ramp}(\psi)$ and cutoff angle of the hanging wall by lower flat $\left(\theta_{1}\right)$ of fault-propagation fold in the section of Lines 7, 8 , and 9 by plotting internal bisecting angles of chevron fold $\left(\gamma^{*}\right)$ and footwall cutoff angle by ramp $\left(\theta_{2}\right)$ in the graph of Suppe and Medwedeff (1990). Please see detailed discussions in the text. The symbols representing the fault bend structure in the sections are: Line 7;, Line 8; $\boldsymbol{\Delta}$, Line 9. 


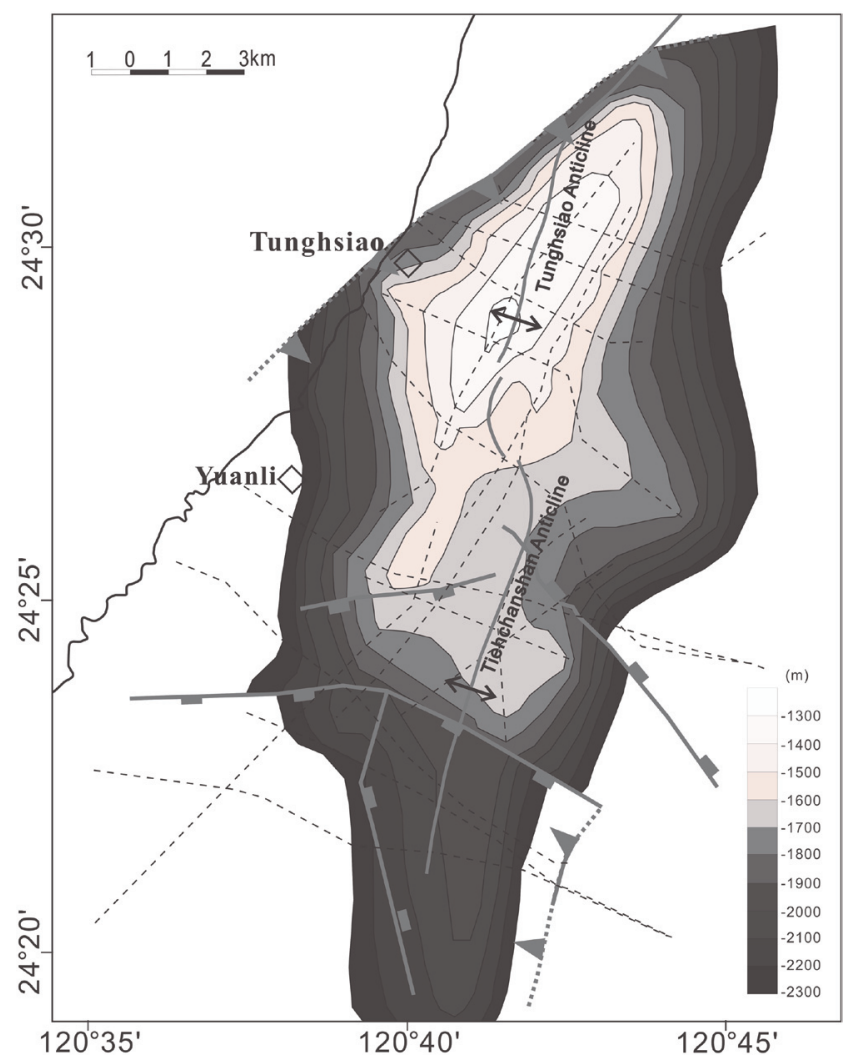

Fig. 8. Contour map of the Kueichulin Formation top. The subsurface anticlinal form is cut off by the fold-forming fault along it northwestern side. The shallow part of the anticline is a perfect closure with fold axis trending NE-SW. To the south, the fold axis turns to NW-SE, where the subsurface transfer zone can be well defined and its location is shifted southward relative to that of the surface one.

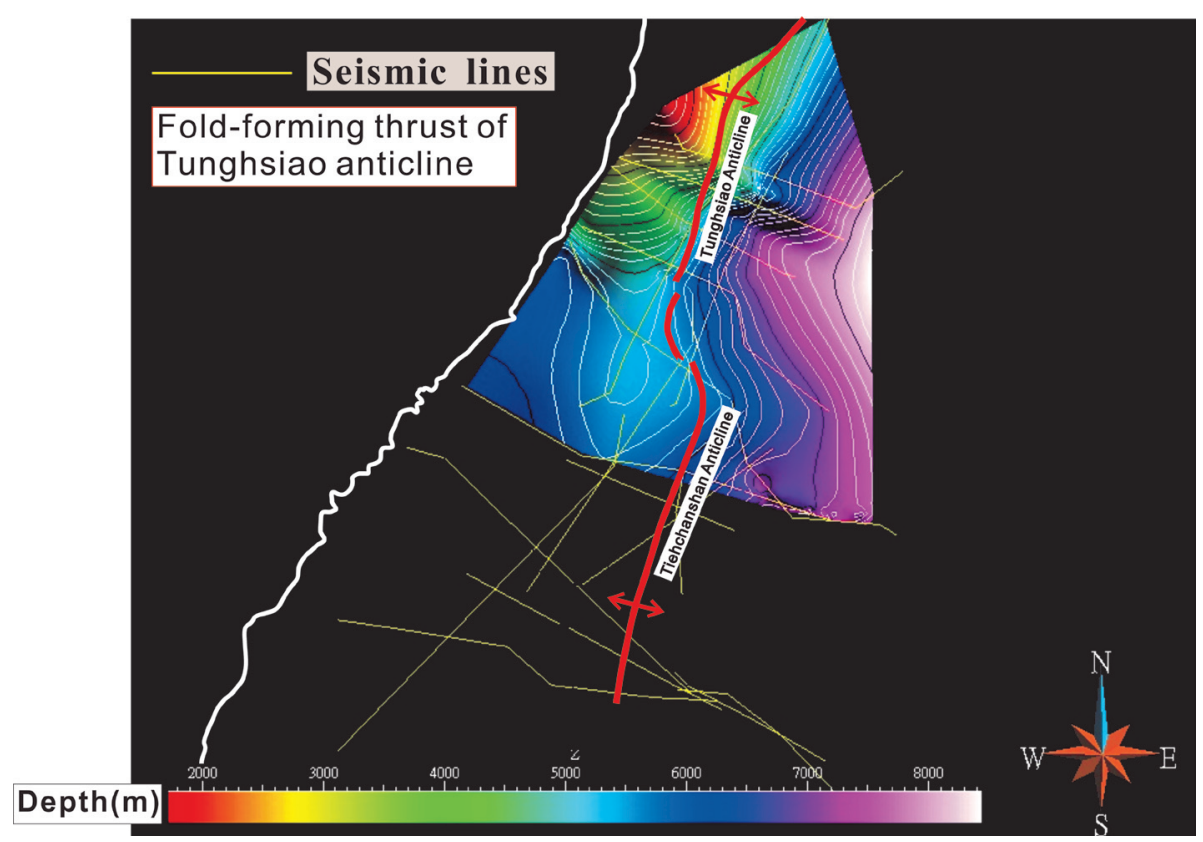

Fig. 9. Contour map of fold-forming thrust of the Tunghsiao anticline. 3-D geometry of the fault plane completely reflects variation in fault shape observed in the sections. Please also notice the change in trend of thrust ramp and see detailed discussions in the text. 
away from the surface transfer zone is highly related to high-angle thrusting cutting down to the basement. In this paper structural sections across the northern part of the Tunghsiao anticline and southern part of the Tiehchanshan anticline were selected for trishear modeling. The shape of high-angle thrust in the sections of Lines 1, 2, and 3 are similar and the one in Line 1 was used as the boundary fault in the model. The shape of high-angle thrust is a straight plane in the sections across the Tiehchanshan anticline and the one in Line 9 was used in the model. We used FaultFold 4.5.4 program of trishear model (Allmendinger 1998) to build a forward model of kinematics and obtain the most probable evolution of fold-forming thrusting and the best-fit fold geometry. The model result also allows us to demonstrate variation in shape of strain ellipses and possible orientation of lines of no finite elongation (LNFE), which may correspond to the orientation of potential fractures.

Tunghsiao anticline two forward models for the thrusting cutting through the Tunghsiao anticline were given to illustrate the results from different kinematics of slip along the fault plane. In the first model fault propagation rate vs. slip rate $(\mathrm{P} / \mathrm{S})$ was set at 20 to simulate slip along a pre-set fault plane with multiple bends. The model result shows that the fault-related fold is an asymmetric anticline with multiple bends (Fig. 10), very different from what is observed in the sections.

In an alternative model, different $\mathrm{P} / \mathrm{S}$ values were given for each segment of thrust with different dip angle. For the segments of thrust in the deeper part $\mathrm{P} / \mathrm{S}$ is 5 in the initial to simulate a propagating fault. The model results (Figs. 11a, b, c) show a gentle monocline fold evolving into a symmetric fold. In the next stage of the model, $\mathrm{P} / \mathrm{S}$ in the middle part of thrust increases to 8 and an asymmetrical shape of fold starts to form (Fig. 11d). In the final stage, P/S even increases to 20 to simulate the thrust breaking through the syncline in front of forelimb and the asymmetrical shape is enhanced (Fig. 11e).

Tiehchanshan anticline the trishear model for the thrust cutting off the Tiehchanshan anticline is simpler than that for the Tunghsiao anticline. The modeled thrust is a straight plane with dip angle of $50^{\circ}$. $\mathrm{P} / \mathrm{S}$ was set at 4 to simulate a propagating fault. The model results show a very asymmetrical shape of fold with a short forelimb and a long backlimb (Fig. 12), very similar to that observed in Line 9 (Fig. 5c).

\section{RESERVOIR STRATIGRAPHY}

In terms of commercial benefit of $\mathrm{CO}_{2}$ sequestration in the future, the Kueichulin Formation has been proposed as the best option for reservoir of $\mathrm{CO}_{2}$ injection (Wu et al. 2007). The formation is underlain by the Chinshui Shale (thicker than $150 \mathrm{~m}$ ) and divided into three members. The subsurface lithofacies logs (Fig. 13), indicate that the reservoirs exist in the Kuantaoshan and Yutengping Sandstones. We selected the Yutengping Sandstone as the target reservoir in this study simply based on the comparison between its reservoir quality and that of the Kuantaoshan Sandstone. Both members contain interlayers of sandstone and shale. Most of sandstones in the the Kuantaoshan Sandstone are coarse- to medium-grained, while those in the Yutengping Sandstone are fine- to medium grained. On the other hand, several single sandstone layers in the Yutengping Sandstone are thicker $(>30 \mathrm{~m})$ and better in sorting than that in the Kuantaoshan Sandstone. An internal research from CPC Corp., Taiwan, indicates that porosity and permeability of the sandstones in the Yutengping Sandstone (24\%, $498 \mathrm{mD}$ ) are greater than that in the Kuantaoshan Sandstone $(23 \%, 342 \mathrm{mD})$ of the Tiehchanshan structure (Yang and Chen 1982). In addition, the Yutengping Sandstone is directly capped by the Chinshui Shale, which is much thicker than the Shiliufen Shale (thinner than $50 \mathrm{~m}$ ) overlying the Kuantaoshan Sandstone. In terms of efficiency and capacity

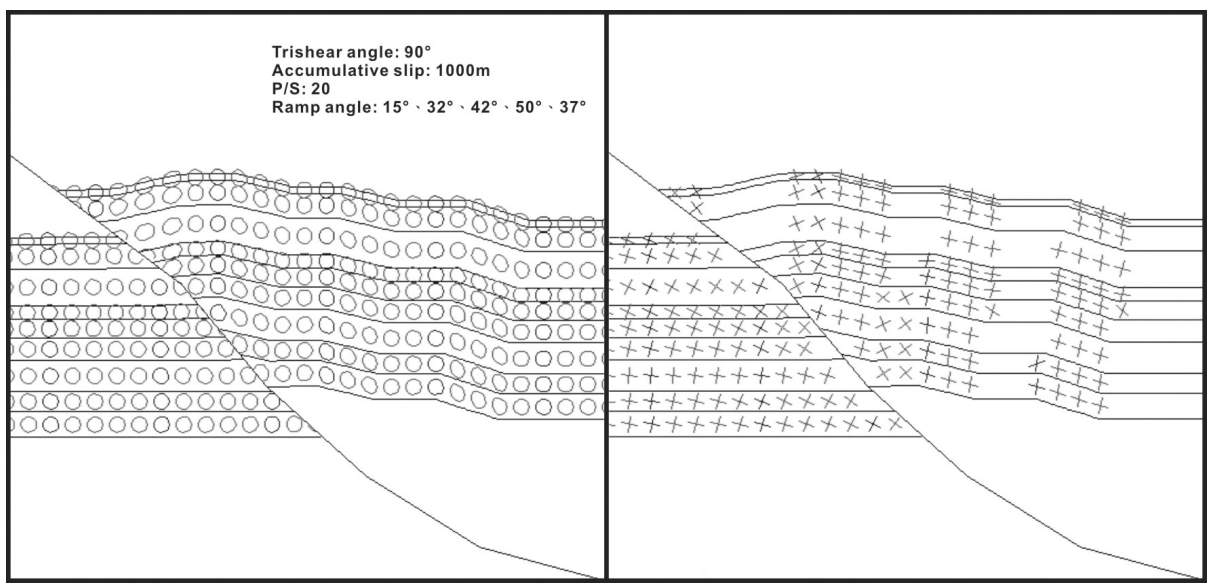

Fig. 10. Trishear model results showing fold shape of the Tunghsiao anticline formed by slip along a pre-set fault plane and the resultant distribution of strain (left) and potential fractures (right). Detailed description of the model is given in the text. 

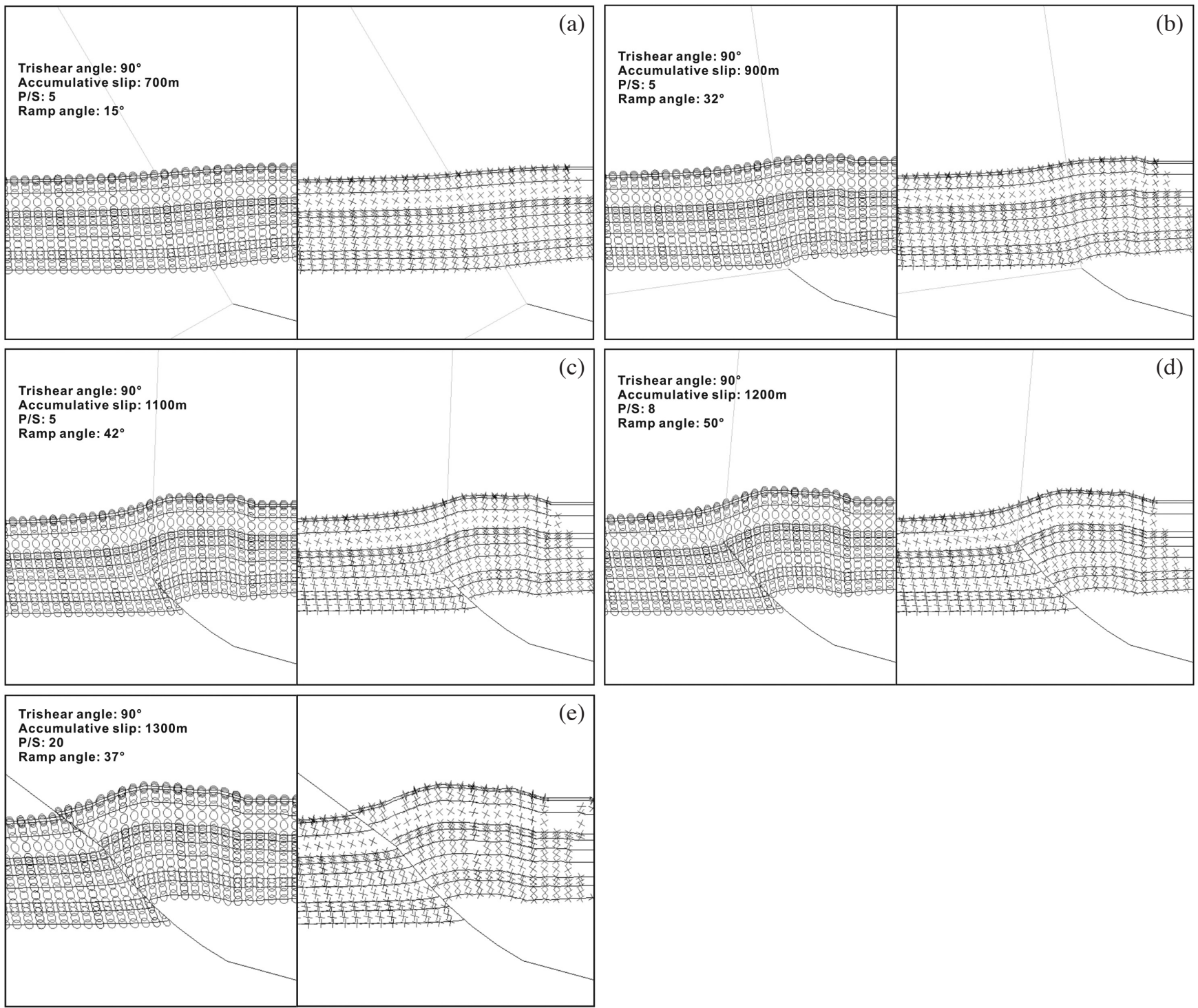

Fig. 11. Alternative trishear model result showing sequentially developed fold shapes of the Tunghsiao anticline formed by slip along a propagating fault plane and a final breaking through the forelimb. The model starts with slip along a low-angle thrust (a), which turns to a higher-angle ramp (b) and its propagating segments with more higher angle (c) (d), and ends with slip breakthrough along a lower-angle thrust (e). The model results also show the distribution of strain (left column) and potential fractures (right column) in each sequentially developed anticline. Detailed description of the model is given in the text.
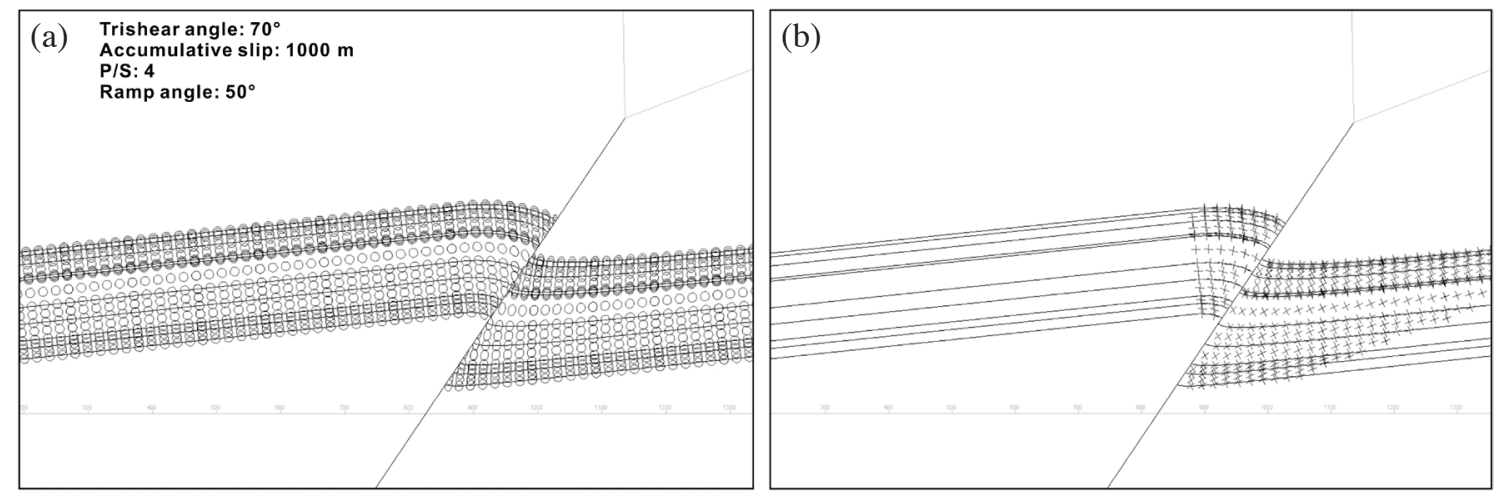

Fig. 12. Trishear model result showing fold shape of the Tiehchanshan anticline formed by slip along a pre-set straight fault plane and the resultant distribution of strain (a) and potential fractures (b). Detailed description of the model is given in the text. 


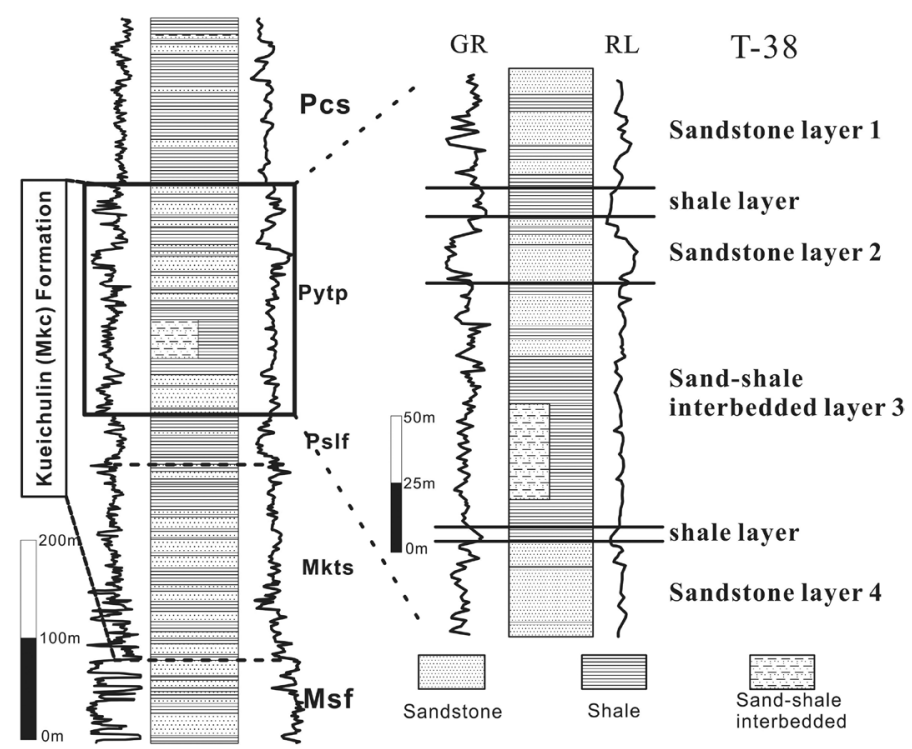

Fig. 13. Typical well logs of the Kueichulin Formation with the overlying Chinshui Shale (left) and the Yutengping Sandstone (right). Lithofacies analysis allows us to divide the Yutengping Sandstone into four layers of sandy strata separated by continuous thin shales.

of $\mathrm{CO}_{2}$ injection in the future, the Yutengping Sandstone would be the better choice.

The isopach map of the Yutengping Sandstone indicates that the thickness of the member is rather uniform across the study area and slightly increasing toward the east (Fig. 14). Lithofacies analysis of the logs further indicates that the member is characterized by interlayers of thick sandstone and thin shale (Fig. 13). Vertical variation in lithofacies of sand-shale successions allowed us to divide the member into four layers of sandy strata, which are separated by pure shales of different thickness (Fig. 13).

In order to assess the continuity of the shales, several stratigraphic sections of the Yutengping Sandstone were built across the anticlines and surface transfer zone (Fig. 15). Boundaries between the interlayers of sandstone and shale can be well traced through the sections with the stacking pattern of coarsening- and fining-upward sequences. In the upper part of the member, a shale layer with significant thickness separates the uppermost sandstone layer (layer no. 1) from the underlying sandstone layers. In terms of sequence stratigraphy (Vail 1987), the shale layer corresponds to deposition during the time of maximum flooding and should distribute through the study area and its adjacent region. The lowermost shale layers, though thinner, are similar in stratigraphic character to that of the uppermost one. The thinnest shale layer in the middle part of the member is interbedded within a long interval of coarsening-upward sequences (layers no. 2 and 3). Still, the shale layer can be traced across the sections.

Each layer of sandy strata has distinct stacking pattern of lithofacies, indicating different ancient depositional environments for all layers (Figs. 13, 15). Isopach maps of the defined sandy strata layers in the stratigraphic sections were constructed to illustrate regional variation in thickness of each layer (Fig. 16). Thickness of every layer increases toward the east or southeast, consistent with that of the entire Yutengping Sandstone (Fig. 14). However, there are some local maxima of layer thickness occurring in the central part of the Tiehchanshan structure, especially for the layers no. 2 and 3 in the middle part of the member. Such variation in local thickness might be due to characteristics of ancient depositional environments.

\section{DISCUSSIONS}

\subsection{New Model for Fault Geometry of the Tiehchanshan Structure}

As mentioned in the chapter of "Regional Geology", different interpretations in the previous geological cross-sections of the Tiehchanshan structure arise from different interpretations on the geometry of fold-forming thrust cutting through the structure in the subsurface, i.e., models of thrust cutting either low angle (Suppe and Namson 1978; Namson 1981; Hung and Wiltschko 1993; Yang et al. 1994, 2007) or high angle (Chung 1996) at the strata. A series of interpreted seismic section in our study illustrate a brand new model of fold-forming thrust, in which the high-angle thrusts in the northern and southern parts of the structure change gradually into the low-angle ones in the transfer zone between two anticlines of opposite vergence. Different thrusting models in the previous studies might only reveal specific parts of subsurface structure of the Tiehchanshan structure.

Another important feature in our new structural model is the west-dipping thrust and its accompanied 


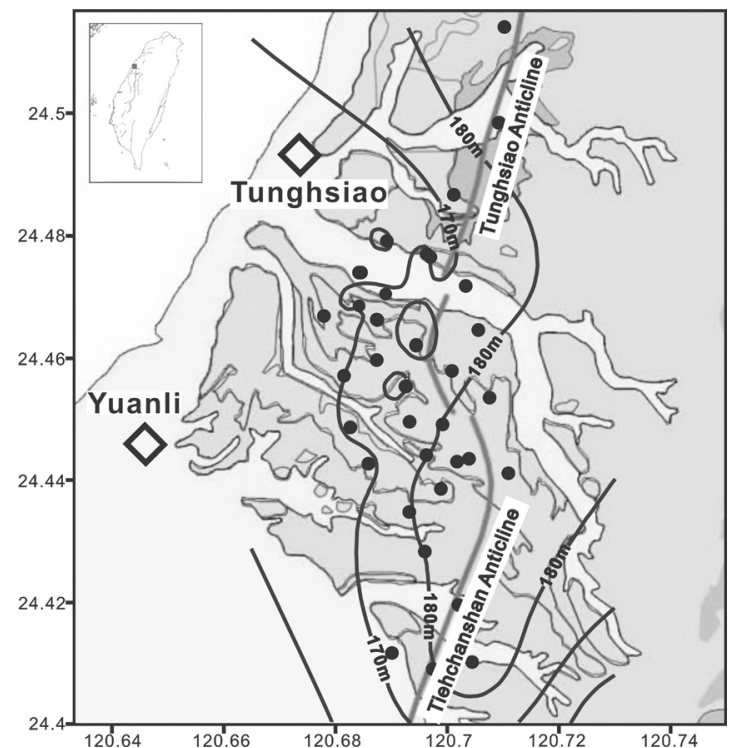

Fig. 14. Isopach map of the Yutengping Sandstone. The map shows that its thickness is gently increasing toward the east with some local maxima of layer thickness.

(a)

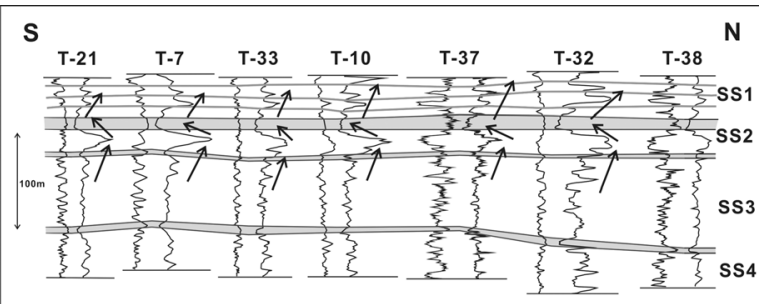

(b)

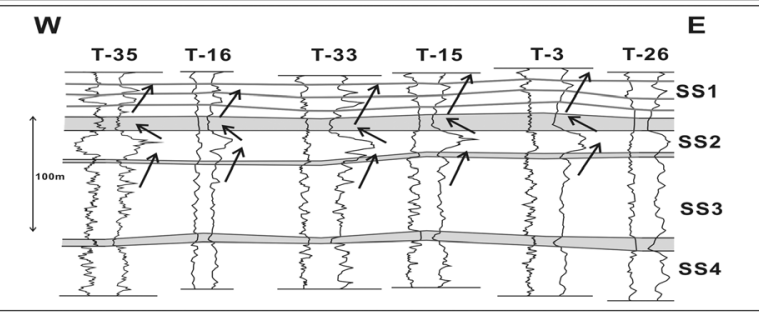

(c)
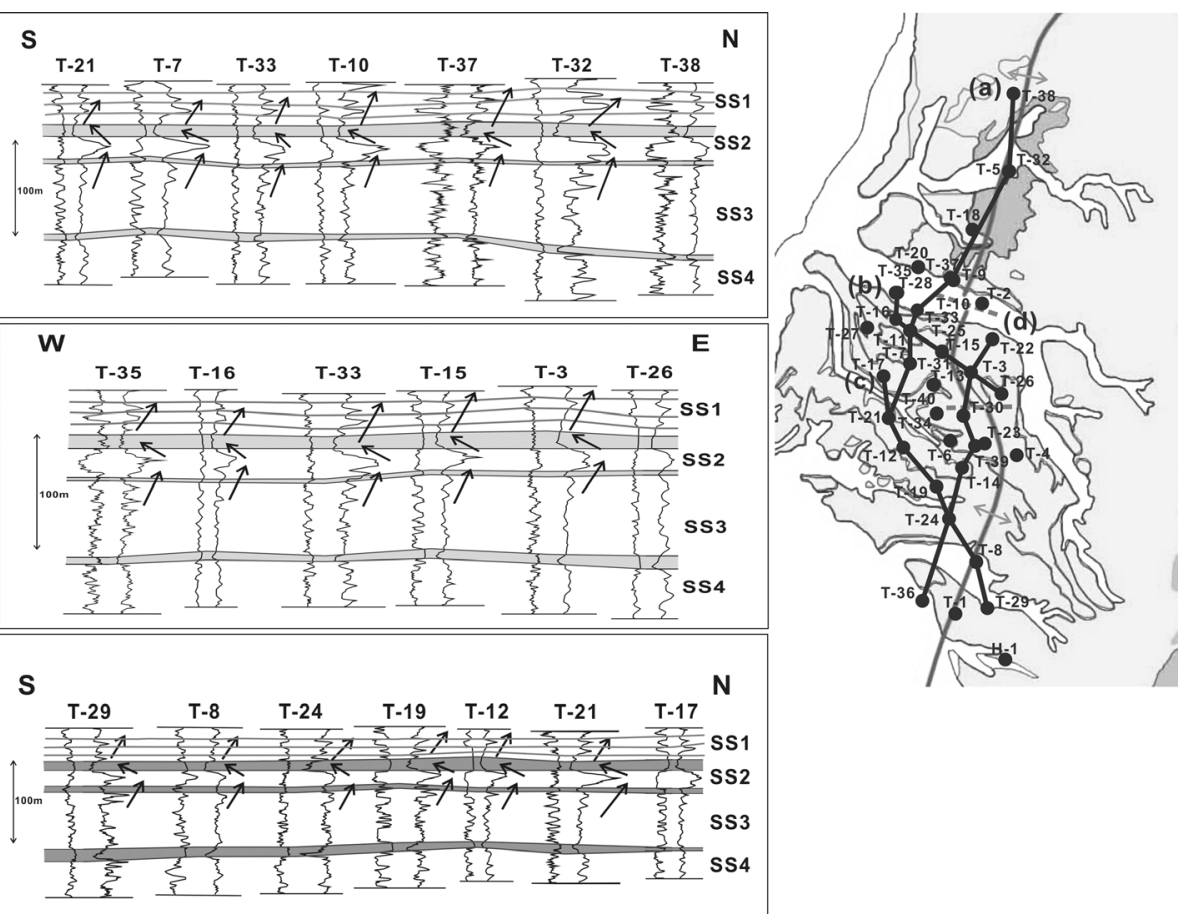

(d)

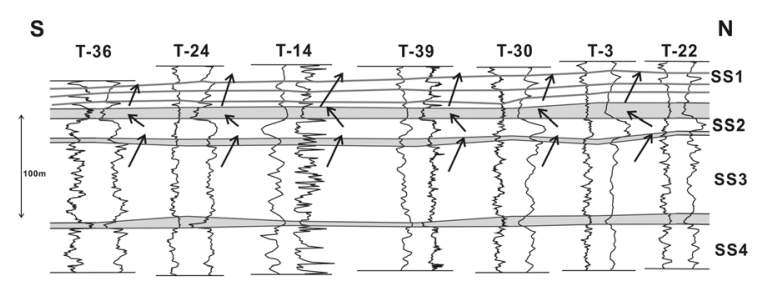

Fig. 15. Stratigraphy sections built with well logs showing layers of sandy strata in the Yutengping Sandstone. The location of the sections (a), (b), (c), and (d) is shown in the map at the right-hand side of the figure. The arrows in the upper part of the member represent the trend of variation in grain size, such as coarsening- and fining upward sequences. The thickest shale at the base of the uppermost layer of sandy strata is well defined by a fining-upward sequence below and coarsening-upward one above. Its implication of sequence stratigraphy and assessment of $\mathrm{CO}_{2}$ is discussed in the text. 


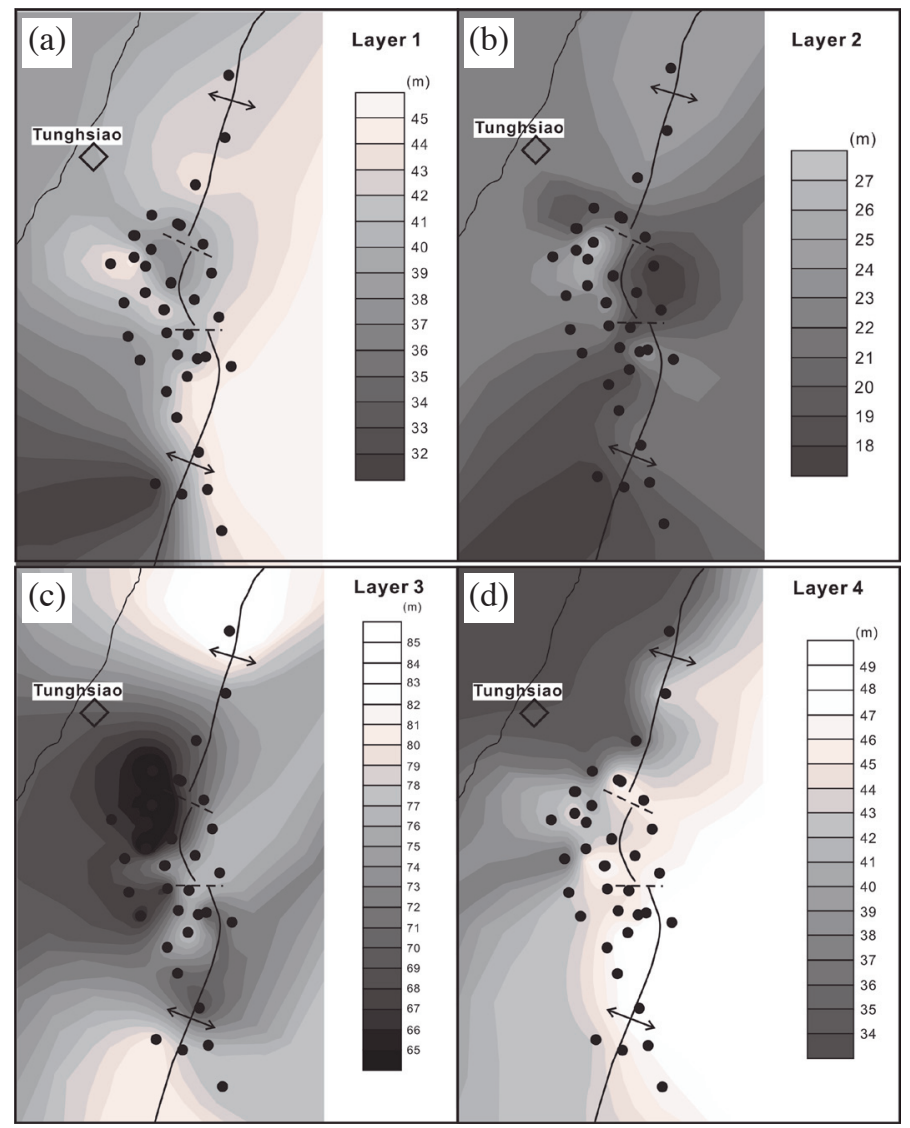

Fig. 16. Isopach maps of the layers of sandy strata in the Yutengping Sandstone constructed with the defined thickness of each layer in Fig. 15. The thickness of layers 1 (a) and 4 (d) increases toward the southeast, while in the layers 2 (b) and 3 (c) there are local thickened strata in the transfer zone.

Tiehchanshan anticline of eastward vergence, opposed to that of the fold-and-thrust belt in western Taiwan. It is not uncommon that backthrusts occur in the frontal part of several orogenic belts; mostly they are a part of the triangle zone and mark the boundary between the orogenic belt and undeformed foreland area (Bank and Warburton 1986; Morley 1986; MacKay et al. 1996; Couzens-Schultz et al. 2003; Duerto et al.2006). In our study area, the backthrust and the other thrust that form the Tunghsiao anticline to the north do not form a triangle zone; rather, they are arranged in an en echelon pattern with the transfer zone in the overlapping area. It is still questionable if they could be attributed to a single deformational event. This is should be addressed by the further studies in the future.

\subsection{Character of Transfer Between Folds of Opposite Vergence}

Structural features in the interpreted seismic sections reveal correspondence of the fold axes with left-lateral offset on the surface to two subsurface folds with opposite vergence. Sections also show that fold and fault shapes change gradually from both ends of the Tiehchanshan structure to- ward the surface transfer zone. On the other hand, surface traces of fold axial surface (Fig. 2) continuously extend into the transfer zone, indicating that the fold axial surfaces are not offset in the subsurface.

In the main part of the Tunghsiao anticline (Lines 1 - 4), while the crest-bounding axial surfaces gradually converge approaching the surface transfer zone, the forelimbbounding axial surfaces are more or less parallel with each other. The axial surface of backlimb syncline runs obliquely in correspondence to decreasing backlimb width toward the surface transfer zone. The number of axial surface increases in the surface transfer zone and its adjacent area to the south. The crest-bounding axial surfaces continuously extend across the surface transfer zone and into the northern part of Tiehchanshan anticline. The axial surfaces of forelimb and backlimb synclines terminate at the southern end of the Tunghsiao anticline but more axial surfaces appear in the surface transfer zone. The number of axial surfaces is reduced again in the main part of the Tiehchanshan anticline. Similarly, the axial surface of the anticline extends northward into the surface transfer zone. At the southeastern side of the surface transfer zone, the axial surfaces strike obliquely to the main trend of the Tiehchanshan structure. 
Surface traces of axial surface reveal three characteristics of the transfer zone in the Tiehchanshan structure. First, the continuous crest-bounding axial surfaces bounding the crest of Tunghsiao anticline strongly suggests that the suspected surface tear fault may not exist in the subsurface. Second, the transfer zone in the subsurface, which can be defined by occurrence of multiple axial surfaces, is much wider than the surface transfer zone in the conventional geological map and located in the area to the south of the surface transfer zone, where the fold axis strikes NW-SE (Fig. 8). Third, two folds of opposite vergence are softly linked in the transfer zone, suggesting that the strata in the subsurface transfer zone have been deformed concurrently by folding on both sides of the zone and form a symmetrical fold shape with multiple bends, such as shown in Lines 5 and 6 (Figs. 4b, c).

\subsection{Correspondence Between Fold and Fault Structures}

Seismic sections across the Tunghsiao anticline show increasing fold symmetry and decreasing dip angle of foldforming thrust toward the surface transfer zone. Correspondence of fold symmetry to dip angle of fold-forming thrust is strongly suggested. Relationship between the fold and fault shapes can also be illustrated by comparison between 3-D geometry of the Tunghsiao anticline (Fig. 8) and the foldforming thrust (Fig. 9). The most prominent characteristics is that the backlimb of fold is parallel with the fault ramp, which strikes NE-SW, changing into NW-SW toward the surface transfer zone and back to NE-SW across the zone.

The 3-D geometry of the Tunghsiao anticline (Fig. 8) also reveals variation in shortening across the structure; the anticline plunges southward rapidly to the south of Line 4, implying that the shortening gradually decreases southward in the subsurface transfer zone.

\subsection{Assessment of Geological Model for $\mathrm{CO}_{2}$ Sequestration}

The potential for carbon sequestration in the Tiehchanshan structure can be assessed by the structural integrity and reservoir characters. The integrity of both anticlinal structures can be evaluated in terms of three geological factors, i.e., structural closure, fault seal and cap rock. Firstly, 3-D geometry of the Tiehchanshan structure (Fig. 8) reveals that the Kueichulin Formation top in the Tunghsiao anticline forms a perfect four-way closure for the storage of $\mathrm{CO}_{2}$ in the subsurface shallower than $1600 \mathrm{~m}$ below sea level. Secondly, at deeper level, say, $1800 \mathrm{~m}$ below sea level, the closure is cut off by the high-angle faults at southern side of the surface transfer zone but still maintain its integrity along the remaining part of boundary. At the levels deeper than $1800 \mathrm{~m}$ below sea level, the closure is cut by more high-angle faults, including the one cutting through the northwestern side of the Tunghsiao anticline and the others cutting off the Tiehchanshan anticline. Finally, the Chinsui Shale, the cap rock, is characterized by significant thickness (greater than $150 \mathrm{~m}$ ) in the study area (Figs, 3, 4, and 5) and invariable lithofacies of shale through the vertical succession (Fig. 13). The formation is not cut off by any faults in the Tunghsiao anticline.

If we consider the thickness of the Kueichulin Formation, the integrity of closure would be also affected by the normal faulting during the pre-orogenic extensional tectonics. The successions of the reservoir, and even the cap rock as well, had been affected by syn-depositional normal faulting and thus cut off by the faults. Syn-depositional normal faults can be identified and are located in the locations where thickness of the Nanchuang Formation changes dramatically, as verified in an N-S trending section (Fig. 17). Thickness of the Kueichulin Formation and the overlying Chinshui Shale is uniform through the entire area and lacks

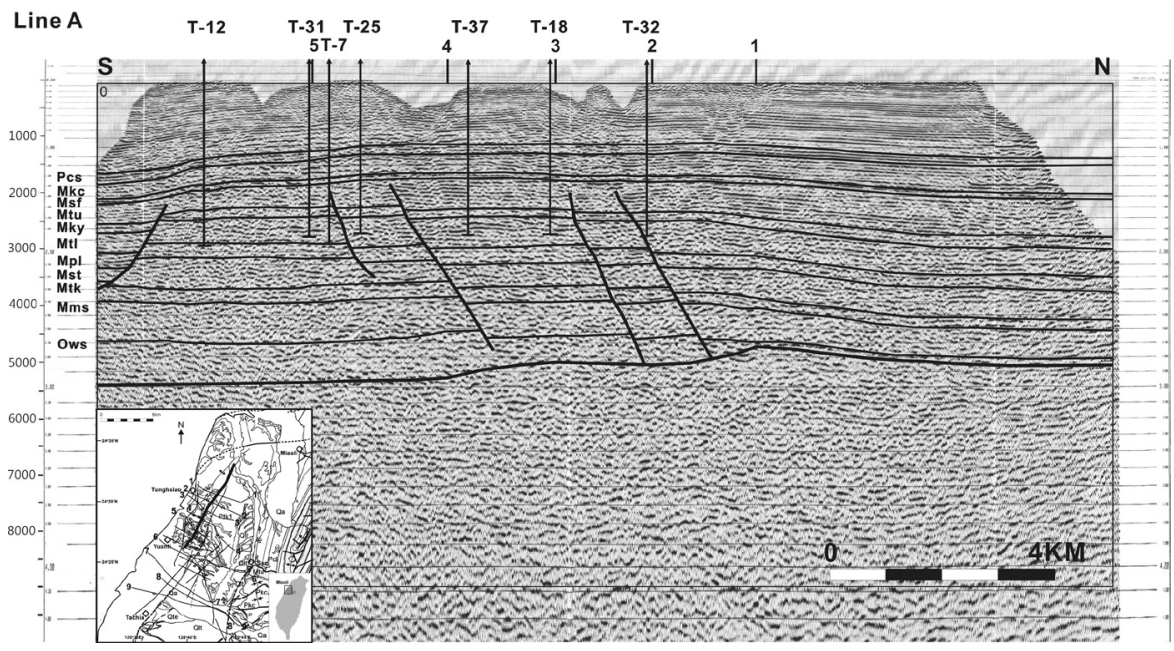

Fig. 17. Interpreted seismic section of Line A running along the crest of the Tiehchanshan structure. This section shows several pre-existing normal faults that cut up to the lower part of the Nanchuang Formation. 
local dramatic changes (Fig. 17), indicating that most of the normal faults were nearly inactive at the time when the strata were deposited.

For a fold with intact geometry, potential fractures would add another influential factor for the assessment of geological model for $\mathrm{CO}_{2}$ sequestration. The above trishear models provided predicted variation in strain and potential fracture for the assessment. The model results of the Tunghsiao anticline (Fig. 11e) predict that strain concentrates in the forelimb and backlimb. The strain in the former is greater than that in the latter; the greatest deformation always happens in the portion closest to the thrust. The orientation of predicted potential fractures varies from the backlimb, where conjugate fractures are nearly orthogonal to the bedding plane, to the forelimb, where fractures are inclined and oblique to the bedding plane. The characteristics of predicted strain and potential fractures would be very important for judging the permeability distribution across the fold structure and selecting optimal injection sites for $\mathrm{CO}_{2}$ storage.

The stratigraphic sections of the most important reservoir, the Yutengping member, show that the thickness of each layer of sandstone strata is uniform at least in the crest part of the structure (Fig. 15). Since the topmost shale has been regarded as the deposition of maximum flooding surface, it turns out to be a second cap rock for the reservoir within the member. Lithofacies change of the layers of sandy strata in the member (Fig. 15) also indicates that the topmost sandy layer could be isolated from the underlying sandy layers by the thickest continuous shale layer, from the viewpoint of flow of injected $\mathrm{CO}_{2}$. The stacking pattern of sand-shale succession also gives very important factor to the $\mathrm{CO}_{2}$ injection simulation.

The geological conditions of the Yutengping Sandstone and the Chinshui Shale, as mentioned above, suggest some merits for the potential of $\mathrm{CO}_{2}$ sequestration: (1) at least $100 \mathrm{~m}$ thick and spatially continuous net sandstone in the Yutengping member (Figs. 13 - 16) can be served as excellent reservoir; (2) $150 \mathrm{~m}$ thick, spatially continuous and invariable lithofacies of shale in the overlying cap rock (Fig. 13) forms intact top seal of the reservoir; (3) thick shale layer at the base of the topmost sandstone layer in the Yutengping member (Fig. 15) forms another seal within the reservoir and may play a role of retardation to the upward flow of the injected $\mathrm{CO}_{2}$; (4) $300 \mathrm{~m}$ of structural closure as a perfect four-way trap of the Tunghsiao anticline (Fig. 8) can be the ideal confinement for $\mathrm{CO}_{2}$ storage without significant risk.

\section{CONCLUSIONS}

(1) In the new model of 3-D geometry of the fold and related fold-forming thrusts, the subsurface geometry of the Tiehchanshan structure is composed of two anticlines of opposite vergence formed by slip along the thrusts with opposite dip direction. The fold of forelandward vergence in the northern part of the structure is a faultpropagation fold accompanied with multiply bended fault breaking through the forelimb. On the other hand, the fold of hinterlandward vergence in the southern part of the structure is a chevron fold formed by slip along a roughly straight thrust dipping at a higher angle and breaking through the forelimb.

(2) In the northern part of the structure, the constructed 3-D geometry of folds corresponds to that of fold-forming thrust quite well; strike of the backlimb is parallel with the fault ramp and changes laterally toward and into the subsurface transfer zone.

(3) The transfer structure in the Tiehchanshan structure is manifested by symmetrical fold and low-angle fold-forming thrust with decreasing slip toward the surface transfer zone and by local change in strike of fold axis in the subsurface transfer zone. On the surface, the traces of axial surfaces extend from both anticlines into the transfer zone, where multiply bended fold structures are influenced by folding on both sides of the zone in the subsurface.

(4) The structural feature of subsurface transfer zone does not match that of the surface one; the folds of opposite vergence are softly linked in the subsurface, implying that the suspected tear fault in the surface transfer zone may not exist in the subsurface. The transfer zone in the subsurface is also much wider and located in the area to the south of the surface transfer zone.

(5) The Yutengping Sandstone is the optimum reservoir and is composed of several sandstone units characterized mostly by coarsening-upward cycles. In terms of sedimentary cycles, the sandstone member can be further divided into four well-defined sandstone layers, which are separated by laterally continuous shale layers.

(6) From the viewpoint of structural and stratigraphic traps, the optimum area for $\mathrm{CO}_{2}$ injection and storage is in the structurally highest part of the Tunghsiao anticline in the northern part of the Tiehchanshan structure. In that area, thickness of the sandstone layers gradually increases to the east, suggesting that the pre-orogenic normal faults might not extend upward to level of the reservoirs and cap rocks in the Tiehchanshan structure. The characteristics that the topmost sandy layer is isolated from the underlying sandy layers by the thickest continuous shale layer would give very important factor to the $\mathrm{CO}_{2}$ injection simulation.

Acknowledgements The authors like to thank Exploration and Development Research Institute, CPC Corporation, Taiwan, for providing invaluable wellbore and seismic data. The authors also thank Ms. Yi-Jin Tang, Mr. Allen Zurei Yang and Ms. Hsing-Yin Fang, from the Department of Earth Sciences, National Cheng Kung University, for compiling the figures and the text. Invaluable comments from 
Dr. Tung-Yi Lee and the other anonymous reviewer are greatly appreciated. All of the research works of this study are the results of the projects (NSC98-3114-E-008-003 and NSC100-3113-E-008-002) supported by National Science Council of Taiwan Government.

\section{REFERENCES}

Allmendinger, R. W., 1998: Inverse and forward numerical modeling of trishear fault-propagation folds. Tectonics, 17, 640-656, doi: 10.1029/98TC01907. [Link]

Baines, S. J. and R. H. Worden, 2004: Geological Storage of Carbon Dioxide, Geol. Soc. Spec. Pub., Vol. 233, Geological Society of London, 255 pp.

Bank, C. J. and J. Warburton, 1986: 'Passive-roof' duplex geometry in the frontal structures of the Kirthar and Sulaiman mountain belts, Pakistan. J. Struct. Geol., 8, 229-237, doi: 10.1016/0191-8141(86)90045-3. [Link]

Chang, S., 1974: Subsurface geologic study of the Miaoli area, Taiwan. Petrol. Geol. Taiwan, 11, 1-25.

Chinese Petroleum Corporation, 1994: Geologic Map of Western Taiwan, Miaoli Sheet $(1: 100,000)$, TPED, CPC, Miaoli City, Taiwan.

Chow, C. T., J. Yuan, K. M Yang, 1986: Geological interpretation of the seismic in the Houpi area, Tainan. Petrol. Geol. Taiwan, 22, 27-53.

Chow, J., K. M. Yang, and H. M. Chen, 1987: Structural traps of the Paiho area, southern Taiwan. Petrol. Geol. Taiwan, 23, 13-39.

Chow, J., K. M. Yang, and H. M. Chen, 1988: Seismic interpretation of the subsurface structures in the YichuChiali Area, southern Taiwan. Petrol. Geol. Taiwan, 24, 60-95.

Chuang, B. I., 2011: 3-D geometry analysis of subsurface geological structure of Tiehchanshan area, Northwestern Taiwan. Master Thesis, National Cheng Kung University, Tainan City, Taiwan, 81 pp. (in Chinese)

Chung, K. C., 1996: Foothills Structure in the Miaoli Area. Master Thesis, National Central University, Taoyuan City, Taiwan, 113 pp.

Couzens-Schultz, B. A., B. C. Vendeville, and D. V. Wiltschko, 2003: Duplex style and triangle zone formation: Insights from physical modeling. J. Struct. Geol., 25, 1623-1644, doi: 10.1016/S0191-8141(03)00004X. [Link]

Cristallini, E. O. and R. W. Allmendinger, 2001: Pseudo 3-D modeling of trishear fault-propagation folding. J. Struct. Geol., 23, 1883-1899, doi: 10.1016/S01918141(01)00034-7. [Link]

Duerto, L., A. Escalona, and P. Mann, 2006: Deep structure of the Merida Andes and Sierra de Perija mountain fronts, Maracaibo Basin, Venezuela. AAPG Bull., 90, 505-528, doi: 10.1306/10080505033. [Link]

Elishewitz, B., 1963: A new interpretation of the structure of the Miaoli area in the light of the decollement tectonics of northwest Taiwan. Petrol. Geol. Taiwan, 2 , 21-45.

Erslev, E. A., 1991: Trishear fault-propagating folding. $\mathrm{Ge}$ ology, 19, 617-620, doi: 10.1130/0091-7613(1991)019 $<0617$ :TFPF>2.3.CO;2. [Link]

Hardy, S. and M. Ford, 1997: Numerical modeling of trishear fault propagation folding. Tectonic, 16, 841-854, doi: 10.1029/97TC01171. [Link]

Ho, C. S., 1982: Tectonic Evolution of Taiwan-Explanatory Text of the Tectonic Map of Taiwan, MOEA, ROC, Taipei City, Taiwan, 126 pp.

Hsiao, P. T., 1974: Subsurface geologic study of the Hsinying coastal plain area, Taiwan. Petrol. Geol. Taiwan, 11, 27-39.

Huang, F. F. W., 1987: Wrench faults in western Taiwan and oil-gas accumulation. Petrol. Geol. Taiwan, 23, $1-12$.

Huang, S. T., R. C. Chen, and W. R. Chi, 1993: Inversion tectonics and evolution of the northern Taihsi Basin, Taiwan. Petrol. Geol. Taiwan, 28, 15-46.

Hubbard, R. J., J. Pape, and D. G. Roberts, 1985: Depositional sequence mapping as a technique to establish tectonic and stratigraphic framework and evaluate hydrocarbon potential on a passive continental margin: Chapter 5. M 39: Seismic Stratigraphy II: An Integrated Approach to Hydrocarbon Exploration, 79-91.

Hung, J. H. and D. V. Wiltschko, 1993: Structure and kinematics of arcuate thrust faults in the Miaoli-Cholan area of western Taiwan. Petrol. Geol. Taiwan, 28, 5996.

Lee, C. I., Y. L. Chang, E.W. Mao, and C.S. Tseng, 1993: Fault reactivation and structural inversion in the Hsinchu-Miaoli area of northern Taiwan. Petrol. Geol. Taiwan, 28, 47-58.

Leu, R. T., C. L. Chianh, and F. W. F. Huang, 1985: Study on the Pachangchi structure, Chaiyi, Taiwan. Petr. Geol. Taiwan, 21, 13-32.

Lin, A. T., A. B. Watts, and S. P. Hesselbo, 2003: Cenozoic stratigraphy and subsidence history of the South China Sea margin in the Taiwan region. Basin Res., 15, 453478, doi: 10.1046/j.1365-2117.2003.00215.x. [Link]

MacKay, P. A., J. L. Varsek, T. E. Kubli, R. G. Dechesne, A. C. Newson, and J. P. Reid, 1996: Triangle zones and tectonics wedges: an introduction. Bull. Can. Petrol. Geol., 44, 139-428.

Morley, C. K., 1986: A classification of thrust fronts. AAPG Bull., 70, 12-25.

Namson, J., 1981: Structure of the western foothills belts, Miaoli-Hsinchu Area, Taiwan: (I) southern part. Petrol. Geol. Taiwan, 18, 31-51.

Namson, J., 1984: Structure of the western foothills belt, Miaoli-Hsinchu area, Taiwan: (III) northern part. Petrol. Geol. Taiwan, 20, 35-52. 
Shaw, J. H., C. D. Connors, and J. Suppe, 2005: Seismic Interpretation of Contractional Fault-related folds: An AAPG Seismic Atlas, Vol. 53, Tulsa, Oklahoma, 156 pp.

Sun, S. C., 1982: The Tertiary basins of offshore Taiwan. $2^{\text {nd }}$ ASCOPT Conference and Exhibition, Manila, Philippine, 126-135.

Suppe, J., 1983: Geometry and kinematics of fault-bend folding. Am. J. Sci., 283, 684-721.

Suppe, J., 1984: Seismic interpretation of the compressively reactivated normal fault near Hsinchu, western Taiwan. Petrol. Geol. Taiwan, 20, 85-96.

Suppe, J., 1986: Reactivated normal faults in the western Taiwan fold-and-thrust belt. Geol. Soc. China Memoir, 7, 187-200

Suppe, J. and D. A. Medwedeff, 1990: Geometry and kinematics of fault-propagation folding. Eclogae. Geol. Helv., 83, 409-454.

Suppe, J. and J. Namson, 1979: Fault-bend origin of frontal folds of the western Taiwan fold-and-thrust belt. Petrol. Geol. Taiwan, 16, 1-18.

Suppe, J., C. D. Connors, and Y. Zhang, 2004: Shear faultbend folding. AAPG Memoir, 82, 303-323.

Tang, C. H., 1977: Late Miocene erosional unconformity on the subsurface Peikang high beneath the Chiayi-Yunlin Coastal Plain, Taiwan. Geol. Soc. China Memoir, 2, 155-167.

Tzeng, J. J., W. W. Wu, and T. L. Chen, 2003: Study of fault-sealing problems in the structure of TCS. Petrol. Geol. Taiwan, 36, 215-240. (in Chinese)

Vail, P. R., 1987: Seismic stratigraphy interpretation using sequence stratigraphy: Part 1: Seismic stratigraphy interpretation procedure. In: Bally, A. W. (Ed.), AAPG Studies in Geology \#27, volume 1: Atlas of Seismic Stratigraphy, 1-10.

Vail, P. R., R. G. Todd, and J. B. Sangree, 1977: Seismic stratigraphy and global changes of sea level: Part 5. Chronostratigraphic significance of seismic reflections: Section 2. Application of seismic reflection configuration to stratigraphic interpretation. M 26: Seismic Stratigraphy--Applications to Hydrocarbon Exploration, 99-116.

Wu, J. C., H. L. Yu, T. H. Hsiuan, and C. H. Fan, 2007: In- vestigation and assessment of $\mathrm{CO}_{2}$ storage in Taichung, Taihsi and Kaohsiung areas. Internal Report, Taiwan, $41 \mathrm{pp}$. (in Chinese)

Wu, M. S., 2010: Hydrocarbon Migration of the Tiehchenshan Gas Field, Miaoli, Northwestern Taiwan. Ph.D. Thesis, National Central University, Taoyuan City, Taiwan, 125 pp. (in Chinese)

Yang, C. C. and J. S. Chen, 1982: Determination of the true formation water salinity and porosity in North Taiwan. Internal report, Taiwan, Vol. 5, 365-366. (in Chinese)

Yang, K. M., J. C. Wu, H. H. Ting, J. B. Wang, W. R. Chi, and C. L. Kuo, 1994: Sequential deformation in foothills belt, Hsinchu and Miaoli areas: Implications in hydrocarbon accumulation. Petrol. Geol. Taiwan, 29, 47-74.

Yang, K. M., J. C. Wu, J. C. Wickham, H. H. Ting, J. B. Wang, and W. R. Chi, 1996: Transverse structures in Hsinchu and Miaoli areas: Structural mode and evolution in foothills belt, northwestern Taiwan. Petrol. Geol. Taiwan, 30, 111-150.

Yang, K. M., H. H. Ting, J. C. Wu, and W. R. Chi, 1997: Geological model for complex structures and its implications for hydrocarbon exploration in northwestern Taiwan. Petrol. Geol. Taiwan, 27, 1-42.

Yang, K. M., S. T. Huang, J. C. Wu, H. H. Ting, and W. W. Mei, 2006: A review and some new insights on foreland tectonics in western Taiwan. Int. Geol. Rev., 48, 910-941.

Yang, K. M., S. T. Huang, J. C Wu, H. H. Ting, W. W. Mei, M. Lee, H. H. Hsu and C. J. Lee, 2007: 3D geometry of the Chelungpu thrust system in central Taiwan: Its implications for active tectonics. Terr.Atmos. Ocean.Sci., 18,143-181, doi: 10.3319/TAO.2007.18.2.143(TCDP). [Link]

Yuan, J., J. T. Chen, C. T. Chow, K. M. Yang, H. M. Chen, H. R. Lo, 1989: Evolution of Tertiary basins of western Taiwan and appraisal of hydrocarbon potentialitiesNorthern Basin and Peikang High region. Chinese Petroleum Corporation, Miaoli City, Taiwan, 366 pp. (in Chinese)

Zehnder, A. T. and R. W. Allmendinger, 2000: Velocity field for the trishear model. Jour. Struc. Geol., 22, 1009-1014. 